\title{
Impact of elevated anti-apoptotic MCL-1 and BCL-2 on the development and treatment of MLL-AF9 AML in mice
}

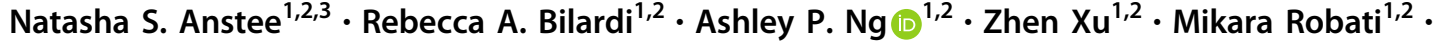 \\ Cassandra J. Vandenberg ${ }^{1,2} \cdot$ Suzanne Cory $\mathbb{1}^{1,2}$
}

Received: 6 November 2017 / Revised: 19 September 2018 / Accepted: 20 September 2018 / Published online: 23 November 2018

(c) The Author(s) 2018. This article is published with open access

\begin{abstract}
Many acute myeloid leukaemias (AMLs) express high levels of BCL-2 and MCL-1, especially after therapy. To test the impact of these anti-apoptotic proteins on AML development and treatment, we used haemopoietic reconstitution to generate $M L L-A F 9$ AMLs expressing $B C L-2$ or $M c l-1$ transgenes. AMLs with elevated BCL-2 or MCL-1 had a higher proportion of mature myeloid cells but, like conventional MLL-AF9 AMLs, were readily transplantable. Short-term cell lines established from multiple primary AMLs of each genotype were tested in vitro for susceptibility to chemotherapeutics currently used for treating AML (daunorubicin, etoposide, cytarabine); the proteasome inhibitor bortezomib; CDK7/9 inhibitors; and BH3 mimetics, which bind and inhibit pro-survival proteins. The BH3 mimetics tested, alone and in combination with the other drugs, were: ABT-737 which, like its clinical counterpart navitoclax, targets BCL-2, BCL- $\mathrm{X}_{\mathrm{L}}$ and BCL-W; BCL-2-specific ABT-199 (venetoclax); BCL-X $\mathrm{L}_{\mathrm{L}}$-specific A-1331852; and S63845, a new MCL-1-specific BH3 mimetic. As single agents, daunorubicin and bortezomib had the greatest efficacy. Elevated MCL-1 or BCL-2 reduced sensitivity to daunorubicin but, surprisingly, not to bortezomib. MCL-1 markedly enhanced resistance to ABT-737 and ABT-199 but not S63845, and BCL-2 increased resistance to S63845 but not to ABT-737 or ABT-199. Notable synergies were achieved by combining BH3 mimetics with daunorubicin: S63845 increased the sensitivity of both MCL-1 and BCL-2 overexpressing MLL-AF9 AMLs, and ABT-737 aided in killing those overexpressing BCL-2. Synergy between daunorubicin and ABT-199 was also apparent in vivo, although not curative. Impressive synergistic responses were achieved for human $M L L$-fusion AML cell lines treated with daunorubicin plus either ABT-737, ABT-199 or S63845, and with ABT-199 plus S63845, with or without daunorubicin. Our data suggest that AML patients may benefit from combining conventional cytotoxic drugs with BH3 mimetics targeting BCL-2 or MCL-1 or, if tolerated, both these agents.
\end{abstract}

Co-first authors: Natasha S. Anstee, Rebecca A Bilardi.

Co-senior authors: Cassandra J. Vandenberg, Suzanne Cory.

Edited by: S. Kaufmann.

Electronic supplementary material The online version of this article (https://doi.org/10.1038/s41418-018-0209-1) contains supplementary material, which is available to authorized users.

Suzanne Cory

cory@wehi.edu.au

1 Walter and Eliza Hall Institute of Medical Research, Melbourne, Victoria 3052, Australia

2 Department of Medical Biology, University of Melbourne, Melbourne, Victoria 3010, Australia

3 Present address: Deutsches Krebsforschungszentrum (DKFZ), Experimental Hematology Division, 69120 Heidelberg, Germany

\section{Introduction}

Acute myeloid leukaemia (AML) is a relentless proliferation of myeloid cells that results in catastrophic bone marrow failure. Although AML can arise from diverse types of genetic changes, individual tumours generally carry only two to four driver mutations [1]. Balanced chromosomal translocation/inversion events giving rise to chimaeric fusion genes are common in AML, particularly in children and younger adults and in therapy-induced AML. Many of these involve the $M L L$ (mixed lineage leukaemia) gene located on chromosome 11 band q23, which encodes a large multi-domain epigenetic regulator [2]. The translocation breakpoint separates the N-terminal DNA binding domain of MLL from its C-terminal histone $\mathrm{H} 3$ lysine 4 (H3K4) methyl transferase domain, thereby disabling its methyl 
transferase activity. The eight genes that most frequently recombine with $M L L$ in translocations encode proteins involved in multi-component transcription elongation complexes [3]. Therefore, most MLL translocations, including the $\mathrm{t}(9 ; 11)$ that produces the MLL-AF9 fusion gene, deregulate transcription of MLL target genes [4, 5].

Many AML patients have a dismal prognosis and more effective therapies are sorely needed [6]. Standard treatment involves administration of cytarabine (ara-C) together with an anthracycline (usually daunorubicin or idarubicin) and sometimes also etoposide [6]. While cytarabine interferes with DNA replication, provoking premature chain termination [7], the anthracylines and etoposide inhibit topoisomerase II, increasing the frequency of double-stranded breaks [8]. Anthracyclines are also believed to generate reactive oxygen species and inhibit DNA and RNA synthesis [9]. All these agents invoke apoptosis via the intrinsic (also called mitochondrial) apoptosis pathway, which is regulated by the BCL-2 protein family.

BCL-2 family members serve as a cellular life/death switch (reviewed in ref. [10]). BCL-2 and its closest relatives (BCL- $\mathrm{X}_{\mathrm{L}}, \mathrm{BCL}-\mathrm{W}, \mathrm{MCL}-1$ and $\left.\mathrm{A} 1 / \mathrm{BFL}-1\right)$ promote cell survival by preventing activation of structurally similar but pro-apoptotic relatives BAX and BAK on the mitochondrial outer membrane (MOM). Stress signals, such as DNA damage or oncogene expression, upregulate distant relatives known as BH3-only (BCL-2 homology domain 3 -only) proteins, which bind tightly via their $\mathrm{BH} 3$ domains to the hydrophobic surface groove of the pro-survival proteins, thereby preventing their restraint of BAX and BAK. Certain BH3-only proteins (BIM, tBID, PUMA and possibly others) can also bind transiently to the surface groove of BAX and BAK, inducing a major conformational change that prompts homo-dimerisation. BAX/BAK homo-dimers aggregate to form homo-oligomeric pores, through which cytochrome c egresses and initiates activation of caspases that cleave vital cellular proteins.

Many AMLs express high levels of pro-survival BCL-2 or MCL-1 [11-13], especially upon relapse after therapy [14]. Importantly, using conditional gene deletion in mice, MCL-1 has been shown to be essential for the development and sustained growth of AML induced by $c-M y c$ or $M L L-$ fusion genes $[11,15]$. These observations led us to test the impact of overexpression of MCL-1 or BCL-2 on the development and treatment of $M L L-A F 9$ AML in mice. In particular, we were keen to test responsiveness to recently developed BH3 mimetics (drugs that mimic BH3-only proteins) and to agents reported to downregulate MCL-1, such as CDK7/9 inhibitors [16, 17] and the proteasome inhibitor bortezomib [18], which is being trialled clinically for AML [19].

\section{Results}

\section{Generation of murine MLL-AF9 AMLs overexpressing BCL-2 or MCL-1}

We have previously developed transgenic mice with panhaemopoietic overexpression of human BCL-2 or mouse MCL-1 protein [20, 21]. To generate MLL-AF9 AMLs, foetal liver haemopoietic stem and progenitor cells (HSPCs) from these and WT mice (all C57BL/6-Ly5.2) were infected with $M L L-A F 9 / G F P$ or GFP (control) retroviruses and transplanted into sublethally irradiated C57BL/6-Ly5.1 recipient mice (Fig. 1a). For brevity, the reconstituted mice are designated hereafter according to the genotype of the donor foetal liver cells and the virus used (e.g. WT/GFP indicates mice reconstituted with WT foetal liver cells infected with control $G F P$ virus and $M c l-1 \operatorname{tg} / M L L-A F 9$ indicates mice reconstituted with $\mathrm{Mcl}$-ltg foetal liver cells infected with $M L L-A F 9 / G F P$ virus).

\section{Overexpression of MCL-1 or BCL-2 exacerbates MLL- AF9 AML}

Three weeks after reconstitution, most MLL-AF9 mice, especially those transplanted with infected cells from $\mathrm{Mcl}$ Itg or $B C L-2 \operatorname{tg}$ mice, had elevated white blood cell counts and enlarged spleens compared to the corresponding control GFP mice (Fig. 1b, c). Even at this early time point, the blood, spleen and bone marrow of the MLL-AF9 mice was replete with donor-derived provirus-expressing (Ly5.2 ${ }^{+} \mathrm{GFP}^{+}$) cells having a myeloid $\left(\mathrm{Macl}^{+}\right)$phenotype (Supplementary Figure S1 and Table S1).

Despite provoking more severe early leukocytosis, overexpression of MCL-1 or BCL-2 did not accelerate morbidity (Fig. 1d). Irrespective of whether their reconstituting stem/progenitor cells were WT, $M c l-1$ tg or $B C L$ $2 \operatorname{tg}$ in genotype, all MLL-AF9 mice required ethical euthanasia within 60 days, whereas the corresponding control GFP mice remained healthy until they were culled (70-90 d). The spleen, bone marrow and blood of the sick mice were dominated by donor-derived $\left(\mathrm{Ly} 5.2^{+} \mathrm{GFP}^{+}\right.$) myeloid $\left(\mathrm{Macl}^{+} \mathrm{Grl}^{-}\right.$and $\mathrm{Mac1}^{+} \mathrm{Grl}^{+}$) cells (Supplementary Figure S2). Of note, the AML phenotype appeared more extreme in terminally ill $M c l-1 \operatorname{tg} / M L L-A F 9$ and $B C L-2 \operatorname{tg} /$ $M L L-A F 9$ mice than in WT/MLL-AF9 mice; leukocytosis and splenomegaly were more severe (Fig. 1e, f) and anaemia and thrombocytopenia more pronounced (Fig. 1g, h). Histological analysis (Supplementary Figure S3) revealed total effacement of the bone marrow, disruption of splenic architecture and leucocyte infiltration of organs such as kidney, pancreas and liver.

In general, sick $M c l-1 \mathrm{tg} / M L L-A F 9$ and $B C L-2 \operatorname{tg} / M L L-$ $A F 9$ mice had a higher proportion of mature myeloid cells 

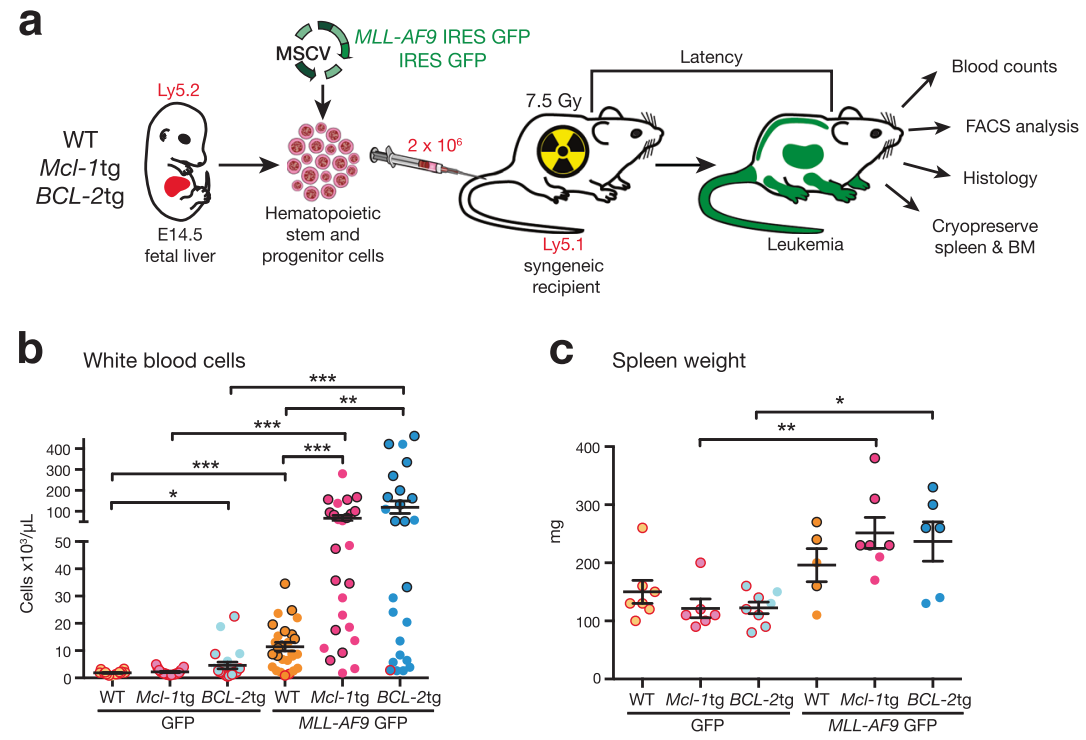

C Spleen weight
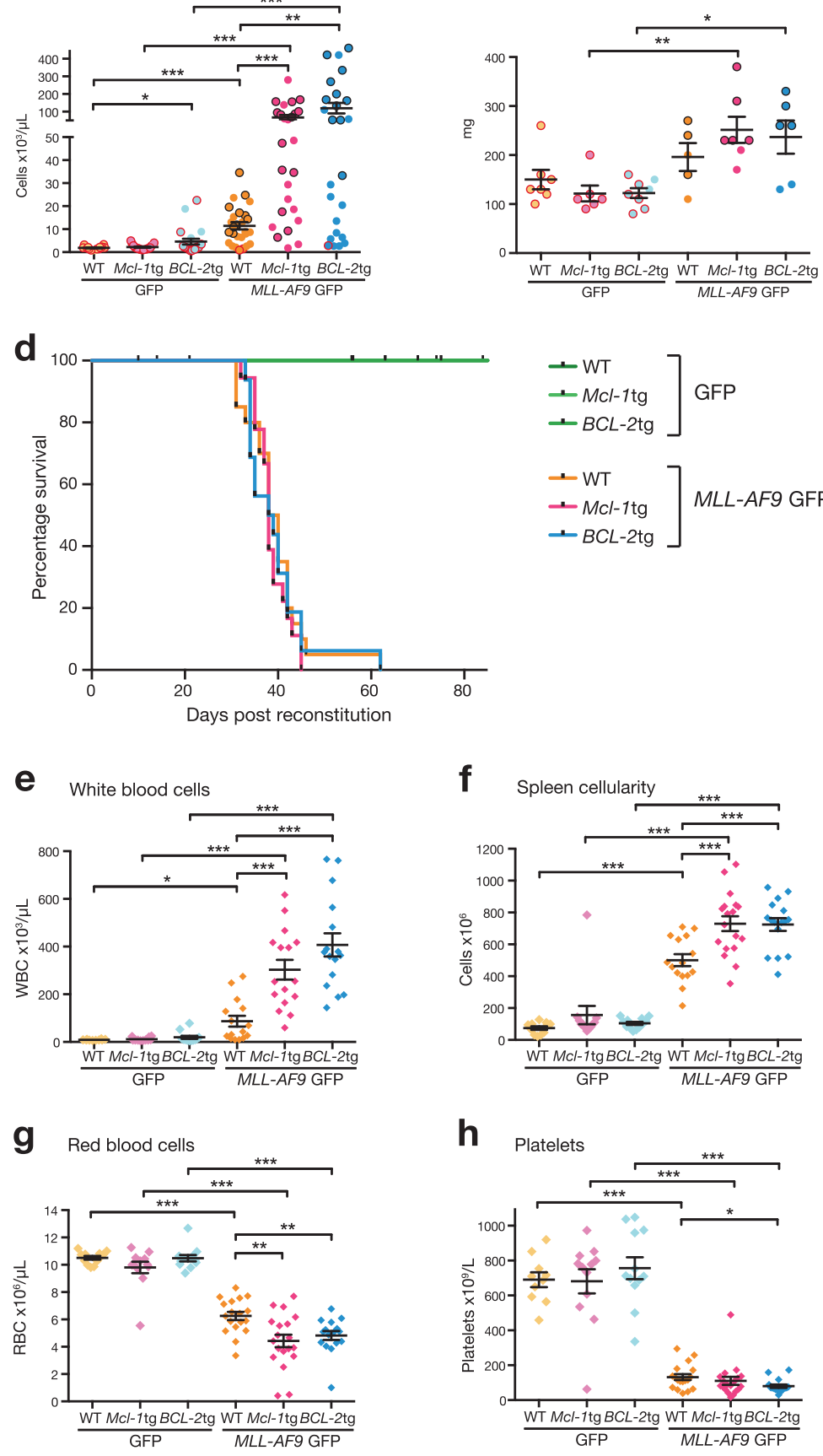

and a lower proportion of blasts than sick WT/MLL-AF9 mice, as evidenced by blood smears, bone marrow cytospins and flow cytometry (Fig. 2, Supplementary Figures S2,

S4, S5a and Table S2). Primary MLL-AF9 AMLs lacking expression of the BH3-only protein BIM [22] had a similar phenotype (Fig. 2b, Supplementary Figure S4). We infer 
Fig. 1 Impact of overexpression of MCL-1 or BCL-2 on the development of MLL-AF9 AML. a Generation of MLL-AF9 AMLs. Haemopoietic stem and progenitor cells from foetal livers of E14.5 WT, vavP-Mcl-1tg or vavP-BCL-2tg embryos were infected with either $M L L-A F 9 / G F P$ or control GFP MSCV virus and transplanted into sublethally irradiated $(7.5 \mathrm{~Gy})$ Ly5.1 recipients $\left(2 \times 10^{6}\right.$ cells/mouse $)$. Mice developing leukaemia were autopsied, subjected to haemopoietic and histologic analysis and their spleen and bone marrow cells were cryopreserved. b, $\mathbf{c}$ Overexpression of MCL-1 or BCL-2 provokes early elevation of myeloid cells. $3 \mathrm{wk}$ analysis of (b) blood leucocytes and (c) spleen weight in mice reconstituted with WT/GFP (light orange, $n=7-18$ ), $M c l$ - 1 tg/GFP (light pink, $n=6-19$ ), $B C L$-2tg/GFP (light blue, $n=8-22$ ), WT/MLL-AF9 (orange, $n=5-27$ ), Mcl-1tg/ $M L L-A F 9$ (pink, $n=7-26$ ) or $B C L-2 \operatorname{tg} / M L L-A F 9$ (blue, $n=6-25$ ) cells. Each dot represents one mouse and mean \pm S.E.M is indicated. $* p<0.05, * * p<0.01, * * * p<0.001$, calculated by Student's $T$-test with Welch's correction. d Overexpression of MCL-1 or BCL-2 does not affect morbidity. Kaplan-Meier plot showing the survival of mice transplanted with WT/MLL-AF9 (orange, $n=20$ ), Mcl-1tg/MLL-AF9 (pink, $n=18$ ), $B C L-2 \operatorname{tg} / M L L-A F 9$ (blue, $n=17$ ) or GFP control (green, $n=12-13$ ) cells. Mice were monitored regularly and euthanased when their symptoms dictated ethical endpoint. Control GFP mice remained healthy until culled (70-90 d). e-h Overexpression of MCL-1 or BCL-2 exacerbates the MLL-AF9 phenotype. Enumeration of (e) blood leucocytes, (f) spleen cells, (g) red blood cells and (h) platelets in sick mice reconstituted with either WT/GFP (light orange, $n=10-12$ ), $M c l-1 \mathrm{tg} / \mathrm{GFP}$ (light pink, $n=12$ ), $B C L-2$ tg/GFP (light blue, $n=12$ ), WT/MLL-AF9 (orange, $n=15-18$ ), $M c l-1 \operatorname{tg} / M L L-A F 9$ (pink, $n=16-19$ ) or $B C L-2 \operatorname{tg} / M L L-A F 9$ (blue, $n=16$ ) cells. Each dot represents one mouse; mean \pm S.E.M is indicated. ${ }^{*} p<0.05$, $* * p<$ $0.01, * * * p<0.001$, calculated by Student's $T$-test with Welch's correction

that the more severe leukocytosis in Mcl-1tg/MLL-AF9, $B C L-2 \operatorname{tg} / M L L-A F 9$ and Bim $^{-1-} / M L L-A F 9$ AML-bearing mice reflects enhanced survival of maturing myeloid cells.

Transplantability tests in non-irradiated congenic mice (Supplementary Table S3) confirmed that all three genotypes were fully malignant. Of note, the transplanted secondary $M c l-1 \mathrm{tg} / M L L-A F 9$ and $B C L-2 \operatorname{tg} / M L L-A F 9$ AMLs still had a greater proportion of differentiated cells than transplanted WT/MLL-AF9 AMLs but the tertiary transplants were all dominated by undifferentiated blasts (Supplementary Figure S5).

\section{Expression of BCL-2 protein family members in primary AMLs}

Western blot analysis was performed on bone marrow cells from 8 to 10 AML-bearing mice of each genotype (Fig. 3). All WT/MLL-AF9 AML samples had readily detectable levels of endogenous MCL-1, BCL-2 and BCL- $\mathrm{X}_{\mathrm{L}}$ (A1 and BCL-W were not analysed). Endogenous MCL-1 levels were comparable between WT/MLL-AF9 and BCL-2tg/ MLL-AF9 AMLs (size overlap with apparent degradation products of transgenic protein prevented the assessment of endogenous MCL-1 in Mcl-1tg/MLL-AF9 AMLs). Interestingly, endogenous BCL-2 and BCL- $\mathrm{X}_{\mathrm{L}}$ were lower in the $B C L-2 \mathrm{tg} / M L L-A F 9$ AMLs than in WT/MLL-AF9 AMLs.
By comparison, although 5 of $8 \mathrm{Mcl}-1 \mathrm{tg} / \mathrm{MLL}$-AF9 AMLs analysed had lower endogenous BCL-2 than the WT AMLs, none had lower BCL- $\mathrm{X}_{\mathrm{L}}$.

Analysis for five BH3-only proteins (Fig. 3, lower panels) showed that all ten WT/MLL-AF9 AMLs expressed relatively uniform levels of BID, PUMA, BIM and (with one exception) BMF, but NOXA expression was prominent in only four. Of note, BIM, BMF and NOXA levels were higher in $M c l-1 \operatorname{tg} / M L L-A F 9$ and $B C L-2 \operatorname{tg} / M L L-A F 9$ than WT/MLL-AF9 tumours.

\section{Impact of MCL-1 or BCL-2 on drug sensitivity}

To gauge drug sensitivity, short-term cell lines were established from multiple $(\geq 5)$ independent primary tumours of each genotype. In addition to standard genotoxic agents (cytarabine, daunorubicin and etoposide), we tested the proteasome inhibitor bortezomib, four CDK7/9 inhibitors, which inhibit transcription [23] and thereby diminish the level of short-lived proteins such as MCL-1 [17], and four BH3 mimetics having different specificities: ABT-737, which binds BCL-2, BCL- $\mathrm{X}_{\mathrm{L}}$ and BCL-W; [24] BCL-2specific ABT-199; [25] MCL-1-specific S63845; [26] and BCL- $\mathrm{X}_{\mathrm{L}}$-specific A-1331852 [27]. Cell viability was determined at $24 \mathrm{~h}$ by measuring metabolic activity (CellTiter-Glo luminescence) (Fig. 4) and, for most agents, by enumerating cells excluding annexin $\mathrm{V}$ and propidium iodide (Supplementary Figure S6). Inhibition of cell death by the pan-caspase inhibitor Q-VD-OPh confirmed that the drugs acted by inducing apoptosis (Supplementary Figure S6c-e).

As single agents, daunorubicin was the most potent of the genotoxic drugs (Fig. 4c) and overexpression of either MCL-1 or BCL-2 increased resistance 13.5 and 5.1 fold respectively. Bortezomib was as active against the WT/ $M L L-A F 9$ AMLs as daunorubicin but, perhaps surprisingly, overexpression of BCL-2 or MCL-1 did not confer resistance. CDK inhibitors flavopiridol, PIK-75 and dinaciclib were more potent than SNS-032 and, while overexpression of MCL-1 or BCL-2 increased resistance, this was more apparent in the apoptosis (Supplementary Figure S6) than the metabolic assay (Fig. 4).

To assess the impact of the CDK inhibitors and bortezomib on apoptosis regulators, western blot analysis was performed on two AML lines of each genotype following drug exposure for $6 \mathrm{~h}$ in the presence of Q-VD-OPh (Fig. 5, Supplementary Figure S7). PIK-75, flavopiridol and SNS032 reduced MCL-1 levels in each genotype in a dosedependent manner, even in the $M c l-1 \operatorname{tg} / M L L-A F 9$ tumours. Responsiveness varied, but in general SNS-032 was less effective at reducing MCL-1 than PIK-75 and flavopiridol. SNS-032 treatment increased NOXA in one $M c l-1 \operatorname{tg} / M L L$ AF9 tumour but not the other. 
a

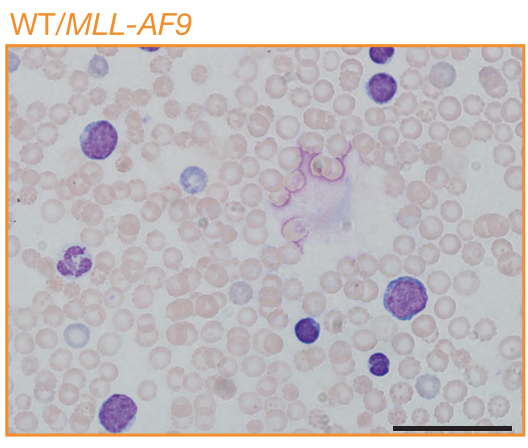

$B C L-2 \operatorname{tg} / M L L-A F 9$

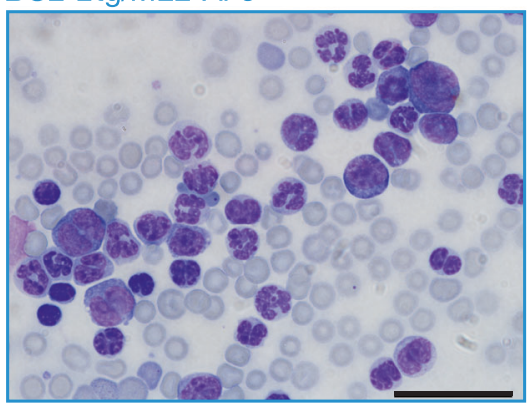

$M c l-1 \mathrm{tg} / M L L-A F 9$

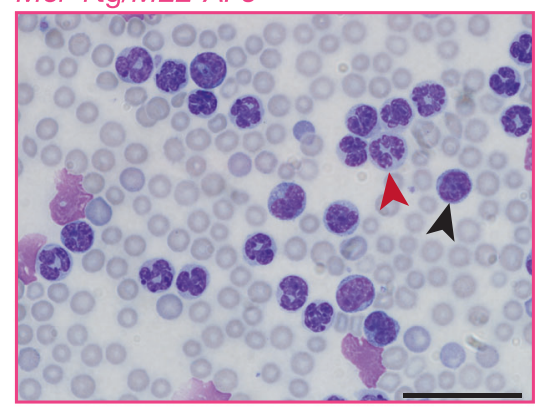

$\mathrm{Bim}^{-/-/ M L L-A F 9}$

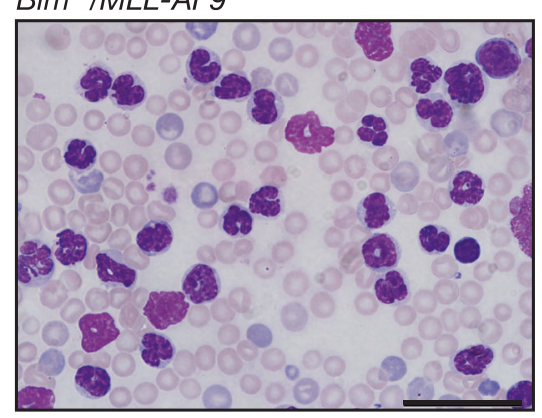

b

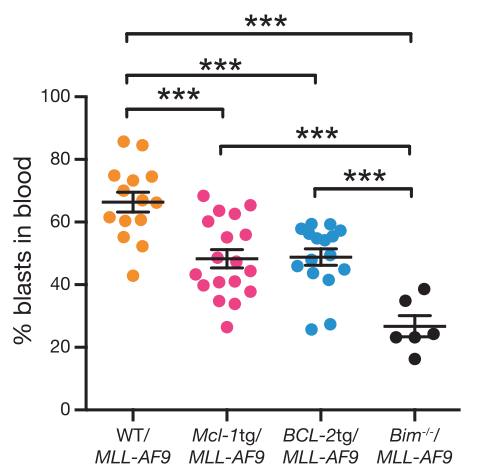

C

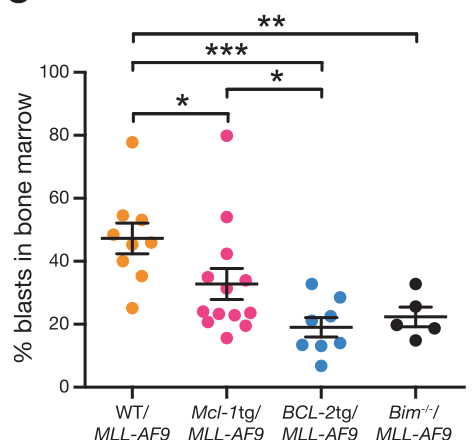

Fig. 2 Leukocytosis in sick primary AML mice. a Blood smears typical of mice reconstituted with stem/progenitor cells of the following genotypes: WT/MLL-AF9 (mouse \#2036), Mcl-1tg/MLL-AF9 (mouse \#2039), BCL-2tg/MLL-AF9 (mouse \#2041) and $\mathrm{Bim}^{-/} / \mathrm{MLL}$ AF9 (mouse \#1250). Scale Bars: $20 \mu \mathrm{m}, \times 1000$ magnification. A typical blast cell is indicated by the black arrowhead and a differentiated myeloid cell with a red arrowhead. (See Supplementary Figure S4 for bone marrow cytospins). b, c Quantification of blast cells (indicated by high nucleus to cytoplasm ratio, scored blinded) in (b) blood and (c) bone marrow of sick primary WT/MLL-AF9 (orange; blood $n=14$, BM $n=9$ ), Mcl-1tg/MLL-AF9 (pink; blood $n=18, \mathrm{BM}$ $n=13$ ), BCL-2tg/MLL-AF9 (blue; blood $n=16$, BM $n=8$ ) and Bim $^{-/} / M L L-A F 9$ (black; blood $n=6, \mathrm{BM} n=5$ ) mice. Each dot represents one mouse $* p<0.05, * * p<0.01, * * * p<0.001$ calculated by Student's $T$-test with Welch's correction

highly resistant to S63845. Conversely, although those overexpressing MCL-1 (pink) were very resistant to ABT737 and ABT-199, as expected, they were just as sensitive to S63845 as WT/MLL-AF9 AMLs, even though S63845 has a 6-fold lower affinity for mouse as compared to human MCL-1 [26].

To test whether the $\mathrm{BH} 3$ mimetics could synergise with any of the drugs under test, we treated 5 independent primary AML lines of each genotype to ABT-737 or S63845, either alone or in combination with the other drugs, at multiple concentrations, using high throughput robotics. Bliss analysis [33, 34] revealed significant synergies (positive scores) for certain drug combinations.

Figure $6 \mathrm{a}, \mathrm{b}$ shows the outcome for daunorubicin. With the WT/MLL-AF9 AMLs (left panels), inclusion of ABT737 (Bliss 87.3) increased sensitivity more than inclusion of S63845 (Bliss 9.5). As anticipated, BCL-2tg/MLL-AF9 AMLs (right panels) were more sensitive to daunorubicin plus ABT-737 (Bliss sum 1314.1) than to daunorubicin plus S63845 (Bliss sum 272.1) and, conversely, the Mcl-ltg/ MLL-AF9 AMLs (middle panels) were more sensitised by 
Fig. 3 Expression of BCL-2 protein family members in primary MLL-AF9 AMLs. Western blot analysis of bone marrow cells from sick primary mice. Lysates run in each lane derived from an individual mouse (mouse numbers shown). Blots are representative of four experiments. In the NOXA blot, NOXA is the more prominent lower band, as determined by probing lysates from $\mathrm{Noxa}^{-/-}$ control cells (not shown) and *indicates a non-specific second band. Molecular weight markers are indicated $(\mathrm{kD})$
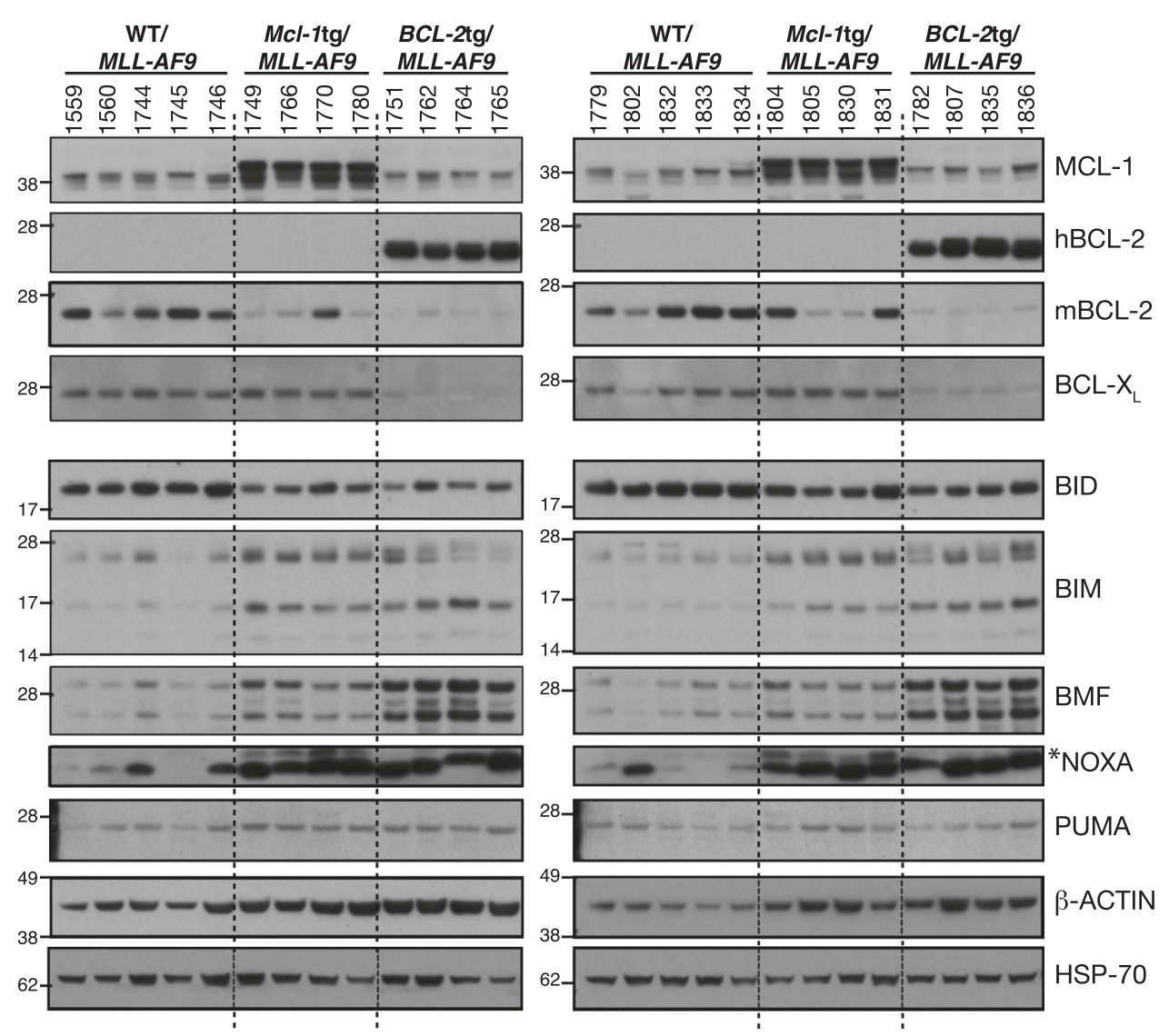

the MCL-1-specific BH3 mimetic (Bliss sum 227.1) than by ABT-737 (Bliss sum 99.1).

A similar pattern was noted with cytarabine, flavopiridol, and PIK-75 (Supplementary Figures S8, S9); the MCL-1 overexpressing AMLs were sensitised by $\mathbf{S} 63845$ to a greater extent than by ABT-737, and the BCL-2 overexpressing AMLs were sensitised more by ABT-737 than by S63845.

Notably, the AMLs also responded well to combining S63845 and ABT-199; any residual resistance to one BH3 mimetic at a particular concentration was significantly or completely overcome by including the other (Fig. 6c, d).

\section{Drug sensitivity of human AML cell lines}

We also tested three human $M L L$-fusion AML cell lines: THP1, MOLM-13 and MV4;11 [35-37] (Fig. 7). Each expresses BCL-2, BCL-W, and MCL-1, with BCL- $\mathrm{X}_{\mathrm{L}}$ and BFL-1 being low or undetectable (Fig. 7b). EC50s were determined using CellTiter-Glo (Fig. 7a). THP-1 cells were the most resistant to daunorubicin, ABT-737 and ABT-199; and MV4;11 cells were the most sensitive to S63845. All lines were resistant to A1331852, which was not tested further.

ABT-737, ABT-199 and S63845 were then tested in combination with daunorubicin (Fig. 7d-f); and ABT-199 plus S63845 was tested with or without daunorubicin (Fig. 7g, h). Each combination was significantly synergistic.
Of note, Bliss scores of $\sim 1000$ were achieved for each human cell line by combining ABT-199 and S63845 (Fig. 7h). BH3 mimetics act downstream of p53 and, as predicted, the combination was effective even for THP-1 cells, which lack functional p53 (see Fig. 7c).

\section{In vivo tests of drug sensitivity}

To investigate whether ABT-737 could increase sensitivity to daunorubicin in vivo, bone marrow cells from 4 independent secondary WT/MLL-AF9 AMLs and BCL-2tg/ MLL-AF9 AMLs were transplanted into non-irradiated syngeneic recipients and treatment was begun 3 days later (Fig. 8a). Although drug treatment extended the life of the animals transplanted with WT/MLL-AF9 AMLs by 5 days, the combination of daunorubicin with ABT-737 was no more effective than daunorubicin alone. Comparable results were obtained for $B C L-2 \operatorname{tg} / M L L-A F 9$ AMLs.

Using the same AMLs, we also tested the efficacy of BCL-2-specific ABT-199 (Fig. 8b, c). ABT-199 had some efficacy as a single agent (compare curves for ABT-199 (yellow) and vehicle controls (pink)), probably because it could be used at a higher concentration $(100 \mathrm{mg} / \mathrm{kg})$ than ABT-737 $(75 \mathrm{mg} / \mathrm{kg})$ and has a somewhat higher affinity for BCL-2 [25]. Using the same dose of daunorubicin $(5 \mathrm{mg} /$ $\mathrm{kg}$ ) as with ABT-737, combination therapy with ABT-199 

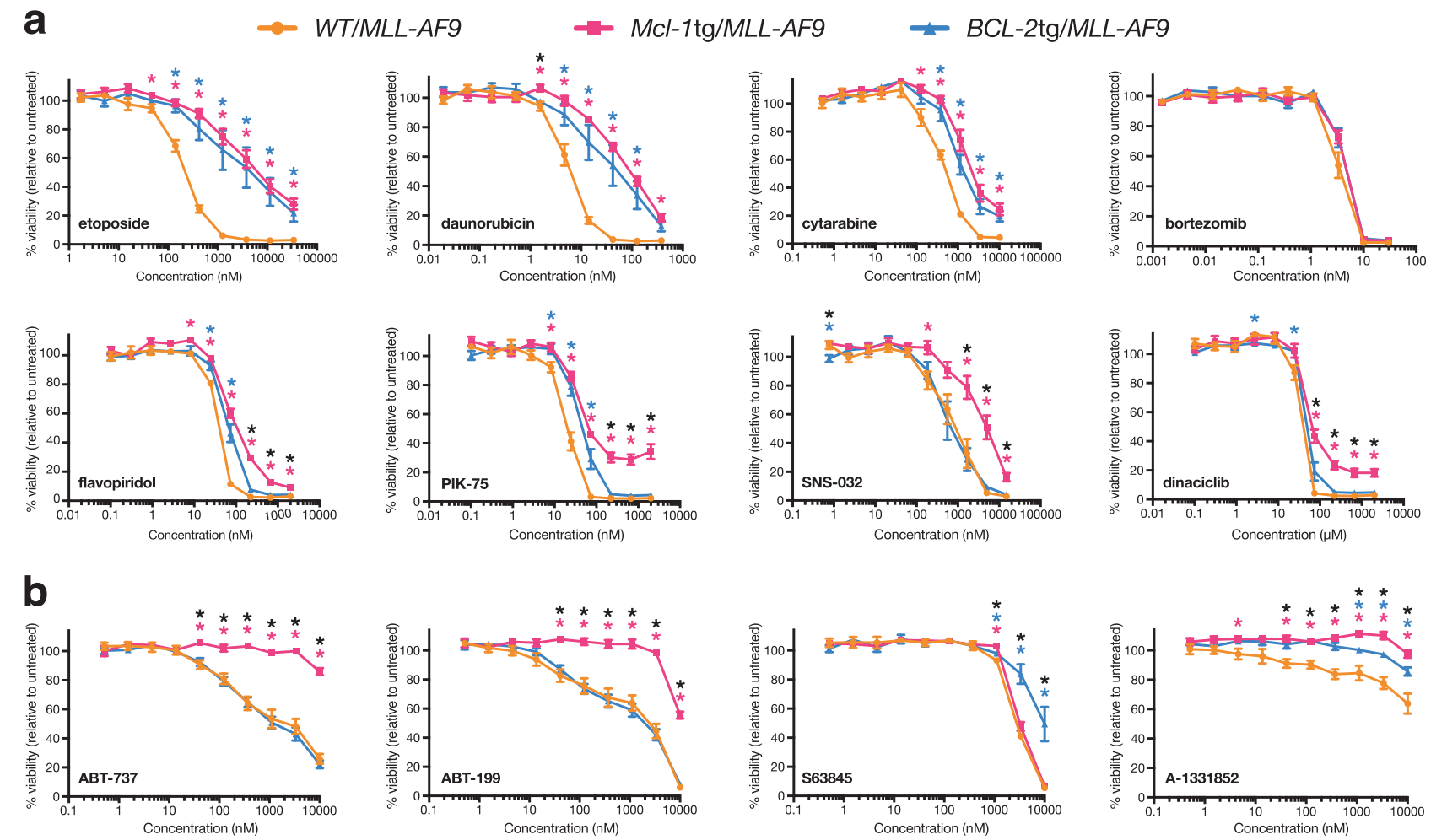

C EC50 of cytotoxic drugs for MLL-AF9 AMLs

\begin{tabular}{|l|c|c|c|}
\hline Drug & WT & Mcl-1tg & BCL-2tg \\
\hline etoposide & $0.20 \mu \mathrm{M}$ & $2.33 \mu \mathrm{M}$ & $1.67 \mu \mathrm{M}$ \\
daunorubicin & $5.91 \mathrm{nM}$ & $79.62 \mathrm{nM}$ & $30.44 \mathrm{nM}$ \\
cytarabine & $0.53 \mu \mathrm{M}$ & $2.18 \mu \mathrm{M}$ & $1.36 \mu \mathrm{M}$ \\
bortezomib & $5.42 \mathrm{nM}$ & $7.73 \mathrm{nM}$ & $7.67 \mathrm{nM}$ \\
\hline flavopiridol & $0.04 \mu \mathrm{M}$ & $0.11 \mu \mathrm{M}$ & $0.08 \mu \mathrm{M}$ \\
PIK-75 & $0.02 \mu \mathrm{M}$ & $0.04 \mu \mathrm{M}$ & $0.05 \mu \mathrm{M}$ \\
SNS-032 & $0.87 \mu \mathrm{M}$ & $5.45 \mu \mathrm{M}$ & $0.73 \mu \mathrm{M}$ \\
dinaciclib & $0.04 \mu \mathrm{M}$ & $0.07 \mu \mathrm{M}$ & $0.06 \mu \mathrm{M}$ \\
\hline ABT-737 & $0.32 \mu \mathrm{M}$ & $\mathrm{nd}$ & $0.40 \mu \mathrm{M}$ \\
ABT-199 & $2.51 \mu \mathrm{M}$ & $\mathrm{nd}$ & $0.89 \mu \mathrm{M}$ \\
S63845 & $2.76 \mu \mathrm{M}$ & $2.18 \mu \mathrm{M}$ & $9.78 \mu \mathrm{M}$ \\
A-1331852 & $\mathrm{nd}$ & $\mathrm{nd}$ & $\mathrm{nd}$ \\
\hline
\end{tabular}

nd: not determined due to a non-sigmoidal graph or the concentrations tested did not span the EC50

Fig. 4 Drug sensitivity of cultured primary MLL-AF9 AMLs. Doseresponse of WT/MLL-AF9 (orange), Mcl-1tg/MLL-AF9 (pink) and $B C L-2 \operatorname{tg} / M L L-A F 9$ (blue) AMLs treated for $24 \mathrm{~h}$ with a chemotherapeutic drugs etoposide, daunorubicin, cytarabine, the proteasome inhibitor bortezomib, and CDK7/9 inhibitors flavopiridol, PIK-75, SNS-032 and dinaciclib and b BH3 mimetics ABT-737 (inhibits BCL2, BCL-X $\mathrm{L}_{\mathrm{L}}, \mathrm{BCL}-\mathrm{W}$ ), ABT-199 (inhibits BCL-2), S63845 (inhibits MCL-1) and A-1331852 (inhibits BCL- $\mathrm{X}_{\mathrm{L}}$ ). Cell viability was measured using CellTiter-Glo Luminescent Assay and indicated relative to untreated control cells (See also Supplementary Figure S6 for viability measured as \% annexin $\mathrm{V}^{-} \mathrm{PI}^{-}$double negative cells). 2-6 technical replicates per independent tumour were averaged and data plotted are average response of 5 independent AMLs per genotype \pm S.E.M. ${ }^{*} p<$

0.05 , calculated by Student's $T$-test with Welch's correction (pink asterisk indicates significant difference between WT/MLL-AF9 versus $M c l-1 \operatorname{tg} / M L L-A F 9$; blue asterisk indicates significant difference between WT/MLL-AF9 versus $B C L-2 \operatorname{tg} / M L L-A F 9$; black asterisk indicates significant difference between $M c l-1 \operatorname{tg} / M L L-A F 9$ versus $B C L-2 \operatorname{tg} / M L L-A F 9)$. Short-term cell lines were derived by culturing bone marrow cells from the following sick primary mice: WT/MLLAF9: \#1746, \#1802, \#1833, \#1834, \#2036; Mcl-1tg/MLL-AF9: \#1750, \#1770, \#1780, \#1805, \#2038; BCL-2tg/MLL-AF9: \#1751, \#1763, $\# 1765, \# 1807, \# 2040$. c EC50s of cytotoxic drugs for primary $M L L$ AF9 AMLs. Values were calculated using GraphPad Prism by logtransforming the data and fitting it to a nonlinear regression 


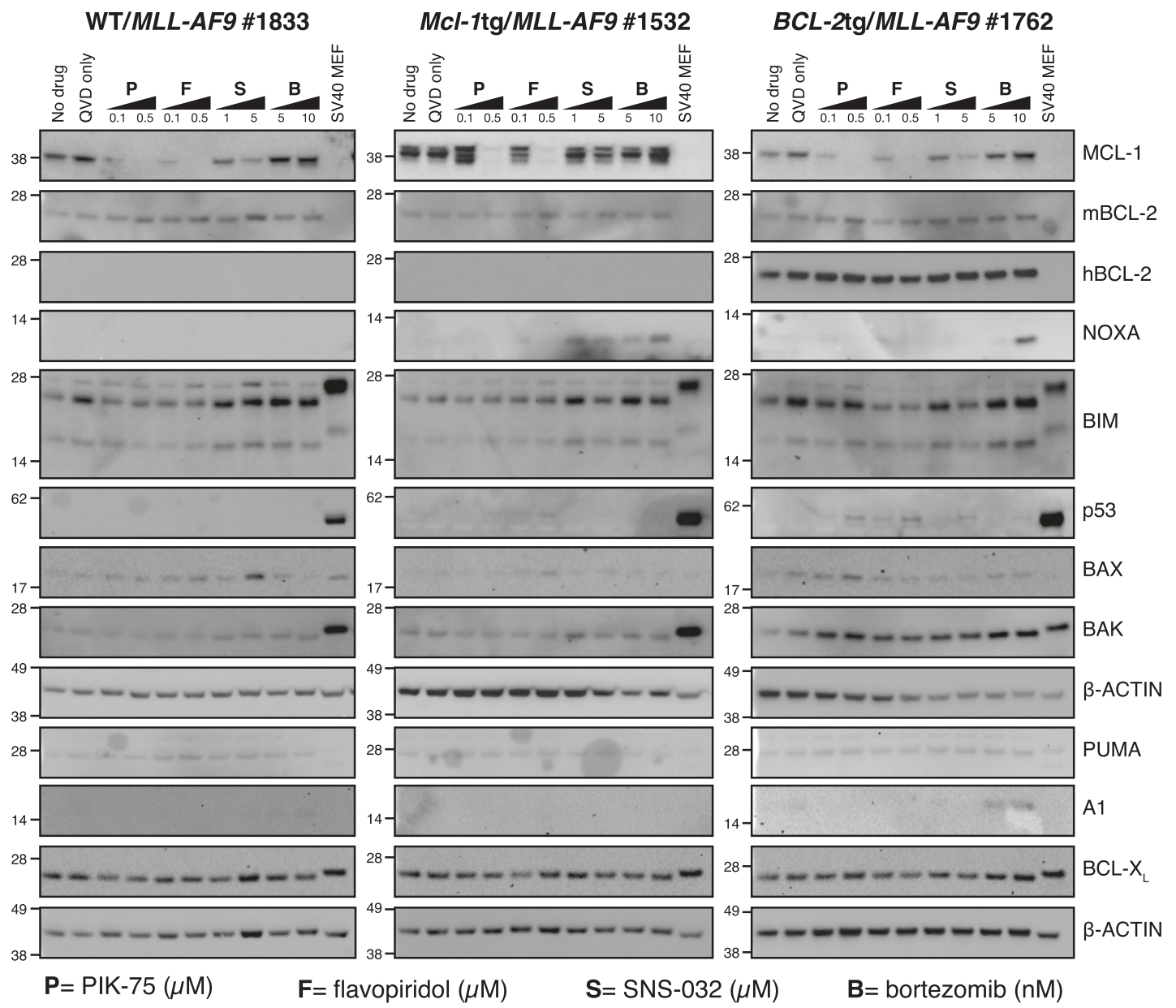

Fig. 5 Impact of CDK inhibitors and bortezomib on apoptosis regulators in primary AML cell lines. Western blot analysis of expression of BCL-2 family proteins and p53 in cell lines derived from primary AMLs: WT/MLL-AF9 (\#1833 left panel), Mcl-1tg/MLL-AF9 (\#1532; central panel) and $B C L-2 \operatorname{tg} / M L L-A F 9$ (\#1762; right panel). Cells were incubated for $6 \mathrm{~h}$ with no drug, Q-VD-OPh (QVD) only or QVD plus PIK-75 (P), flavopiridol (F), SNS-032 (S) or bortezomib (B) at doses

indicated (in $\mu \mathrm{M}$ for $\mathrm{CDK}$ inhibitors and $\mathrm{nM}$ for bortezomib). Representative blots of two experiments with independent tumours (see Supplementary Figure S7 for western blots of WT/MLL-AF9 \#1559, Mcl-1tg/MLL-AF9 \#1766 and BCL-2tg/MLL-AF9 \#1806). SV40 transformed mouse embryo fibroblasts (MEFs) served as a positive control for p53 and $\beta$-ACTIN as a loading control. Molecular weight markers are indicated $(\mathrm{kD})$

was more efficacious than treatment with daunorubicin alone, for tumours of both genotypes (Fig. 8b; $p<0.001$ for WT/MLL-AF9 AMLs, $p<0.05$ for $B C L-2 \mathrm{tg} / M L L-A F 9$ AMLs), although all treated mice still died within 30 days. The benefit of combination therapy with ABT-199 was still apparent at a lower dose of daunorubicin $(3 \mathrm{mg} / \mathrm{kg})$ for $B C L-2 \operatorname{tg} / M L L-A F 9$ AMLs $(p<0.05)$ although not for WT/MLL-AF9 AMLs (Fig. 8c).

We were unable to use S63845 at high enough concentrations to effectively test its efficacy in vivo against the Mcl-1tg/MLL-AF9 AMLs, which overexpress mouse MCL-1.

\section{Discussion}

AML remains a major clinical challenge [32], with little improvement in patient outcomes over the past 30 years.
The high levels of pro-survival proteins BCL-2 and MCL-1 commonly found in AMLs [11, 12,38], especially after relapse [14], are thought to contribute to resistance to therapy. In this study, we directly tested the impact of MCL-1 and BCL-2 using the well-studied MLL-AF9 mouse model.

\section{Impact on AML development}

Elevated expression of BCL-2 or MCL-1 had no significant impact on the kinetics of morbidity of $M L L-A F 9$-driven AML (Fig. 1d), in contrast to $M y c$-driven B lymphoid malignancy, which was markedly accelerated by $B C L-2$ or Mcl-1 transgenes [21, 39]. However, the much faster tumour development in the AML model permits little scope for acceleration. 
a

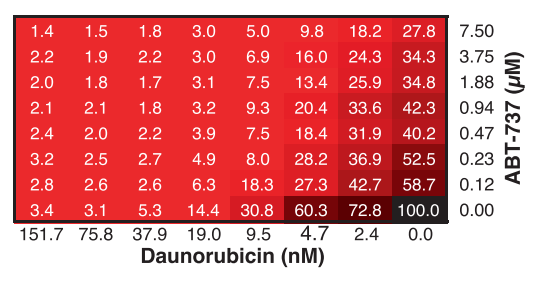

Bliss sum $=87.3$

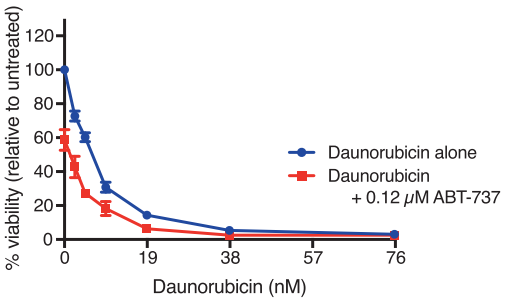

b $\quad W T / M L L-A F 9$

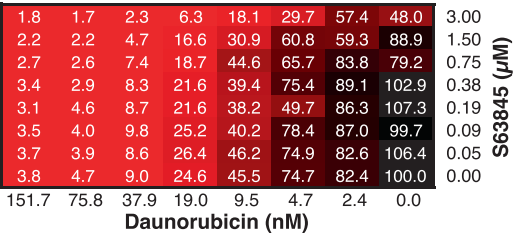

Bliss sum $=9.5$

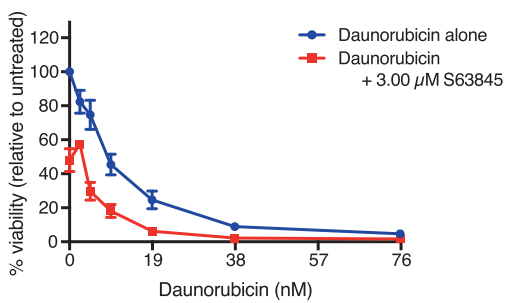

C

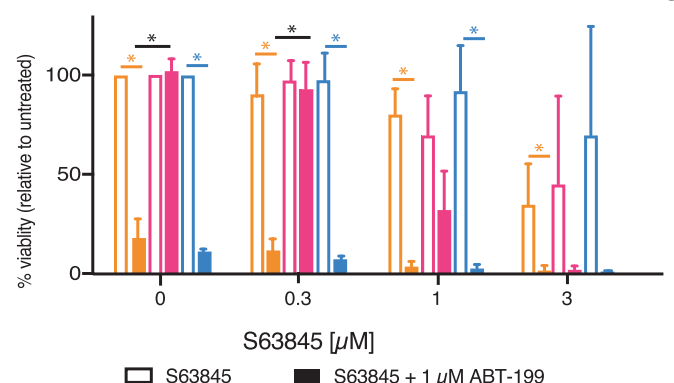

There were, nonetheless, intriguing differences between WT/MLL-AF9 AMLs and those overexpressing BCL-2 or MCL-1. Leukocytosis became apparent earlier and was more severe in the $B C L-2 \operatorname{tg} / M L L-A F 9$ and $M c l-1 \operatorname{tg} / M L L-$ $A F 9$ mice (Fig. 1) and the AML phenotype was more differentiated, as were MLL-AF9 AMLs lacking the proapoptotic BH3-only protein BIM [22] (Fig. 2 and Supplementary Figure S4, S5). These observations suggest that blocking apoptosis enhances the in vivo lifespan of

\section{$B C L-2 \operatorname{tg} / M L L-A F 9$}
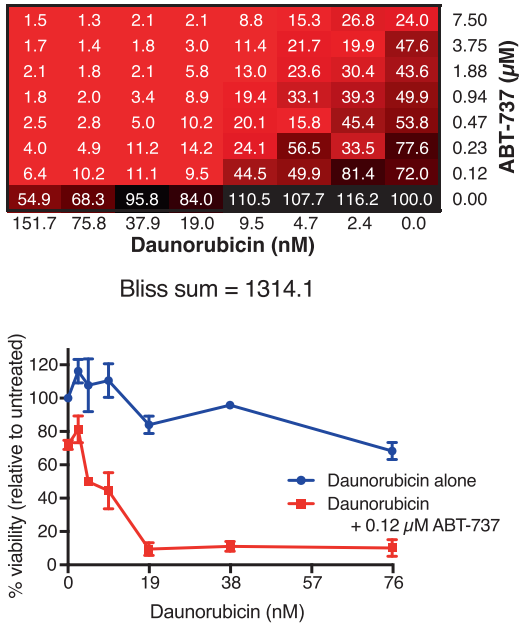

$B C L-2 \operatorname{tg} / M L L-A F 9$
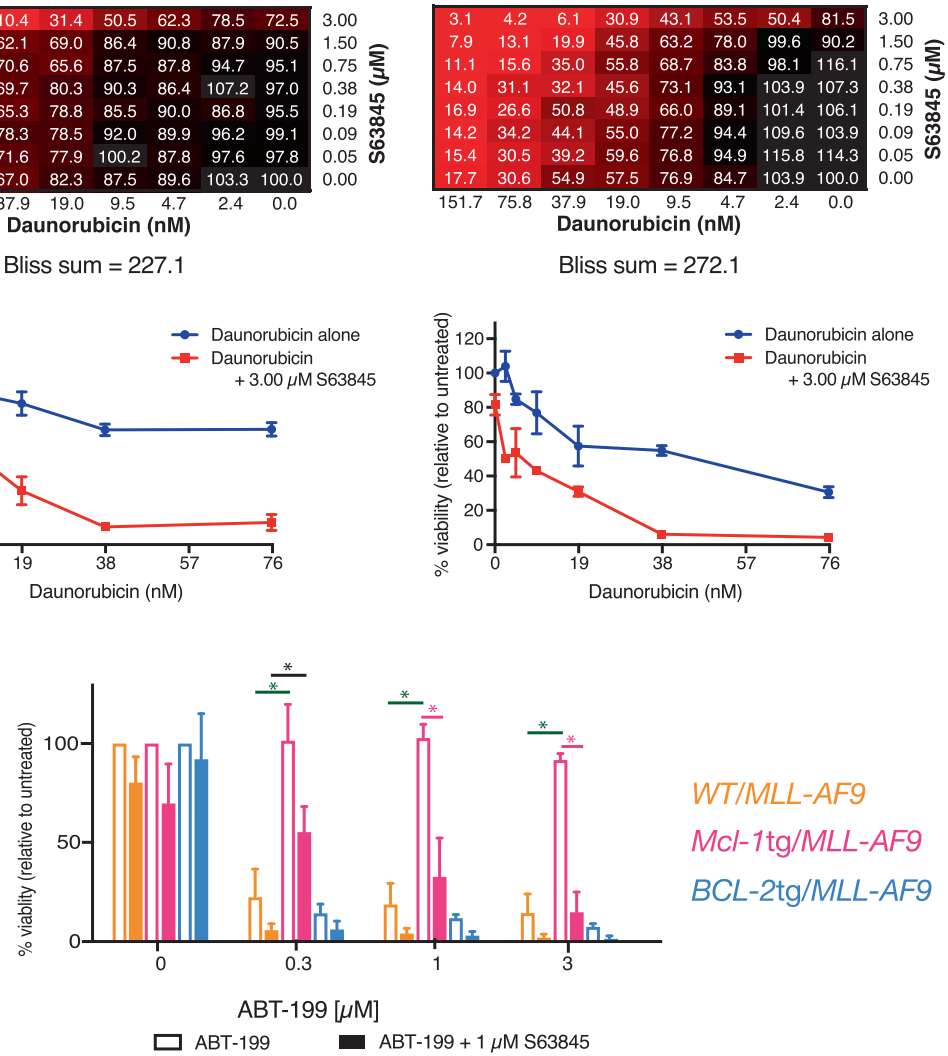

maturing $M L L-A F 9$-driven leucocytes. However, in contrast to results for a mouse model of the myelodysplastic syndrome [40], leukaemic transformation was unaffected, as the $B C L-2 \operatorname{tg} / M L L-A F 9$ and $M c l-1 \operatorname{tg} / M L L-A F 9$ AMLs were fully and serially transplantable in non-irradiated mice (Supplementary Table S3).

Transgenic overexpression of MCL-1 and BCL-2 appeared to modulate the expression pattern of other BCL-2 family members (Fig. 3). Of note, higher levels of 
Fig. 6 Synergy between daunorubicin and BH3 mimetics in vitro. Combination responses of daunorubicin plus a ABT-737 or b S63845 on WT/MLL-AF9 (left), Mcl-1tg/MLL-AF9 (middle) and BCL-2tg/ $M L L-A F 9$ (right) primary AML cell lines as indicated by an $8 \times 8$ matrix informing on viability after $24 \mathrm{~h}$ treatment determined by CellTiter-Glo assay and the sum of Bliss scores across the combination dose matrix. The score for each dose combination is calculated according to the formula $(\mathrm{A}+\mathrm{B})-(\mathrm{A} \times \mathrm{B})$ where $\mathrm{A}$ and $\mathrm{B}$ are the fractional growth inhibitions induced individually by agents $\mathrm{A}$ and $\mathrm{B}$ at that given dose. Also shown is the response to daunorubicin across the dose range as a single agent and in combination with a single dose of (a) ABT-737 $(0.12 \mu \mathrm{M})$ or (b) S63845 $(3.00 \mu \mathrm{M})$. Each matrix is the average response of 3 independent tumours for each genotype. Viability curves indicate mean \pm S.E.M of 3 independent tumours per genotype. Tumours used for treatment with daunorubicin + ABT-737 were WT/MLL-AF9 \#1560, \#2036, \#2037, Mcl-1tg/MLL-AF9 \#1554, \#2038, \#2039, BCL-2tg/MLL-AF9 \#1751, \#2040, \#2041. Tumours used for treatment with daunorubicin $+\mathrm{S} 63845$ were WT/MLL-AF9 \#1746, \#1802, \#1833, Mcl-1tg/MLL-AF9 \#1770, \#1780, \#1805, BCL2tg/MLL-AF9 \#1751, \#1765, \#1807. c, d Responses to combination treatment with BH3 mimetics ABT-199 and S63845 were assessed by culturing primary AML cell lines for $24 \mathrm{~h}$ in varying concentrations of (c) S63845 $\pm 1 \mu \mathrm{M}$ ABT-199 or (d) varying concentrations of ABT$199 \pm 1 \mu$ M S63845. Viability was determined via flow cytometric quantitation of annexin $\mathrm{V}^{-} \mathrm{PI}^{-}$cells and expressed relative to untreated controls. Values are mean \pm SEM of 3-4 independent tumour cell lines per genotype. $* p<0.05$. Orange, pink and blue asterisks indicate significant difference between single agent and combination for that genotype. Black asterisk indicates significant difference between WT/ $M L L-A F 9$ and $M c l-1 \mathrm{tg} / M L L-A F 9$ combination treatments. Green asterisk indicates significant difference between WT/MLL-AF9 and Mcl-1tg/MLL-AF9 single agent treatments. Tumours used were WT/ MLL-AF9 \#1744, \#1802, \#1833, \#1834, Mcl-1tg/MLL-AF9 \#1750, \#1770, \#1780, BCL-2tg/MLL-AF9 \#1751, \#1762, \#1763

BIM, BMF and NOXA were apparent in Mcl-1tg/MLL-AF9 and $B C L-2 \operatorname{tg} / M L L-A F 9$ AMLs than in WT/MLL-AF9 AMLs, suggesting that elevated pro-survival proteins had preserved $M L L-A F 9$-driven cells experiencing stressinduced upregulation of these pro-apoptotic BH3-only proteins. Furthermore, the BCL-2tg/MLL-AF9 AMLs had lower levels of endogenous BCL-2 and BCL- $\mathrm{X}_{\mathrm{L}}$ than the WT/MLL-AF9 AMLs, suggestive of lower selection pressure to upregulate these endogenous pro-survival proteins. Comparable changes were less apparent for the $\mathrm{Mcl}$ $1 \mathrm{tg} / M L L-A F 9$ AMLs, probably because the level of transgenic MCL-1 protein is not as high as that of transgenic BCL-2 [41], although five of eight had lower endogenous BCL-2 than WT/MLL-AF9 AMLs. Overall, these results suggest that $M L L-A F 9$ expression imposes considerable cytotoxic stress on haemopoietic cells, either directly or indirectly, and this selects for upregulation of pro-survival proteins. Genetic studies have shown that endogenous MCL-1 is essential for the development and sustained expansion of AML driven by MLL-fusion genes, whereas BCL-X $\mathrm{L}, \mathrm{BCL}-2$ and $\mathrm{BCL}-\mathrm{W}$ play lesser roles [15].

\section{Impact on drug sensitivity}

In vitro tests of drug sensitivity were performed using shortterm cell lines derived from five primary AMLs of each genotype (Fig. 4, Supplementary Figure S5). Four classes of drugs were used: cytotoxic drugs routinely used to treat AML (daunorubicin, cytarabine and etoposide); the proteasome inhibitor bortezomib, which is being trialled for AML; [19] CDK7/9 inhibitors that inhibit transcription and thereby reduce levels of short-lived proteins such as MCL$1 ;[16,17,42]$ and $\mathrm{BH} 3$ mimetics targeting different prosurvival BCL-2 family members: ABT-737 (which targets BCL-2, BCL-X $\mathrm{L}_{\mathrm{L}}$ and BCL-W) [24, 28], ABT-199 (venetoclax) (specific for BCL-2) [25], A-1331852 (specific for $\mathrm{BCL}_{\mathrm{L}}$ ) [34, 43] and S63845 (specific for MCL-1) [26].

The WT/MLL-AF9 AMLs were far more sensitive to daunorubicin (EC50 $5.9 \mathrm{nM}$ ) than to etoposide or cytarabine (EC50s of $200 \mathrm{nM}$ and $530 \mathrm{nM}$ respectively) and, as predicted, overexpression of MCL-1 or BCL-2 increased resistance (Fig. 4). MCL-1 was as inhibitory as BCL-2, which suggests it is more potent, given the lower level of the transgenic protein [41]. Our gene knock-out studies have previously shown that responsiveness to daunorubicin, etoposide and cytarabine is dependent on the BH3-only proteins PUMA and NOXA and that BIM also plays a role in responsiveness to cytarabine [22].

PIK-75, a dual inhibitor of CDK9 and PI3K, has been shown to be active against cytologically diverse primary human AML samples [17]. However, neither PIK-75 nor the other CDK7/9 inhibitors were as cytotoxic as daunorubicin against the mouse $M L L-A F 9$ AMLs, despite reducing MCL-1 protein levels in a dose-dependent manner, even in the $M c l-1 \operatorname{tg} / M L L-A F 9$ tumours.

In contrast, bortezomib was very potent, even in the face of high BCL-2 or MCL-1. Our previous study [22] showed that NOXA is very important for bortezomib-mediated killing of $M L L-A F 9$ AMLs. NOXA levels are high in most $M L L-A F 9$ AMLs we tested, particularly those overexpressing MCL-1 or BCL-2 (Fig. 3). NOXA strongly binds to and inhibits pro-survival MCL-1 [44, 45], which is vital for the development and sustained growth of AMLs driven by $M L L$-fusion genes [15]. Presumably NOXA levels are sufficiently elevated by bortezomib to overcome MCL-1 even in the $M c l-1 \mathrm{tg} / M L L-A F 9$ AMLs.

$\mathrm{BH} 3$ mimetics bind tightly to the surface groove of their target pro-survival proteins, thereby preventing them from binding to $\mathrm{BH} 3$-only proteins and to activated BAX and/or BAK molecules (see [10, 46] and references therein). In doing so, the $\mathrm{BH} 3$ mimetics increase the availability of BH3-only proteins to carry out their death-promoting functions. As single agents, the $\mathrm{BH} 3$ mimetics were not highly potent against WT/MLL-AF9 AMLs, BCL-X $\mathrm{L}^{-}$ 
a

EC50 of cytotoxic drugs for human MLL-fusion AMLs

\begin{tabular}{|l|l|l|l|}
\hline Drug & THP-1 & Molm-13 & MV4;11 \\
& MLL-AF9 & MLL-AF9 & MLL-AF4 \\
\hline Daunorubicin & $61 \mathrm{nM}$ & $25 \mathrm{nM}$ & $32 \mathrm{nM}$ \\
ABT-737 & $>5 \mu \mathrm{M}$ & $160 \mathrm{nM}$ & $65 \mathrm{nM}$ \\
ABT-199 & $4.3 \mu \mathrm{M}$ & $78 \mathrm{nM}$ & $24 \mathrm{nM}$ \\
A-1331852 & $>5 \mu \mathrm{M}$ & $>5 \mu \mathrm{M}$ & $>5 \mu \mathrm{M}$ \\
S63845 & $56 \mathrm{nM}$ & $51 \mathrm{nM}$ & $13 \mathrm{nM}$ \\
\hline
\end{tabular}

d Daunorubicin+ABT-737

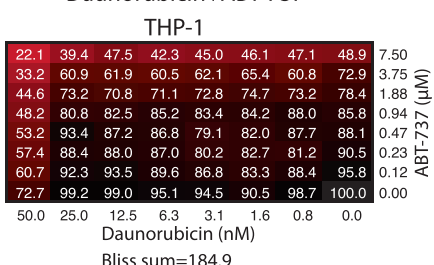

e Daunorubicin+ABT-199

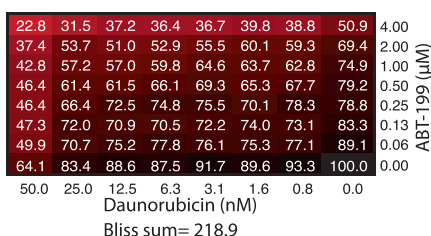

f Daunorubicin+\$63845

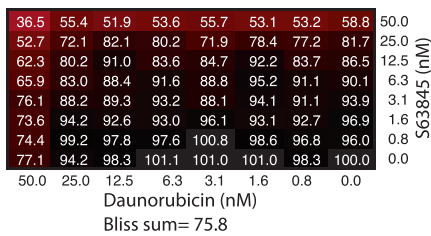

9 Daunorubicin+ABT-199+\$63845
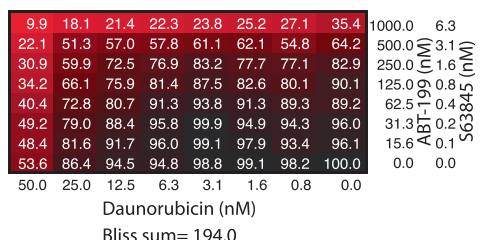

Bliss sum $=194.0$

h ABT-199+\$63845
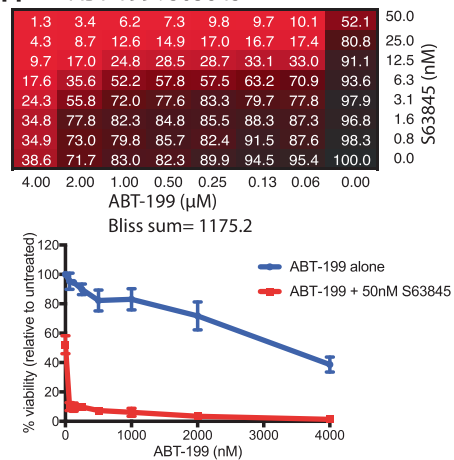

b

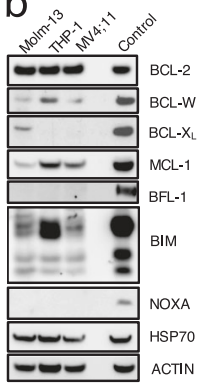

Molm-13
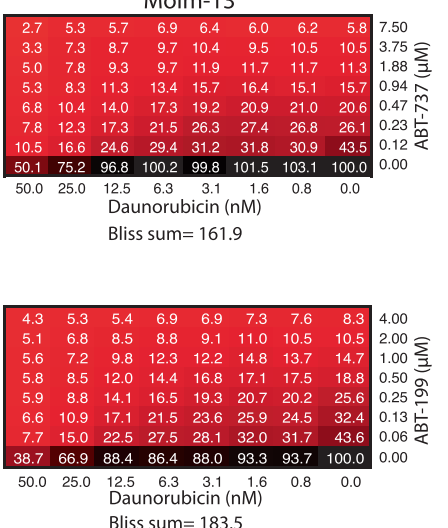

Bliss sum $=183.5$
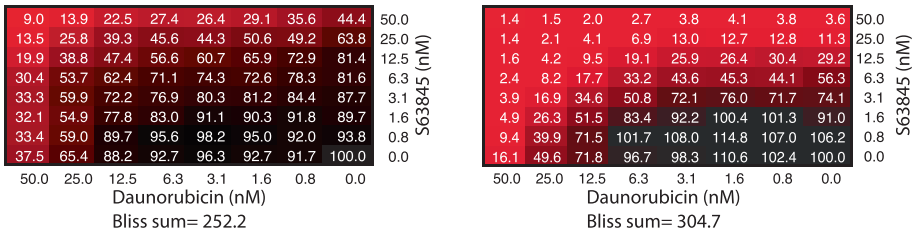

MV4;11
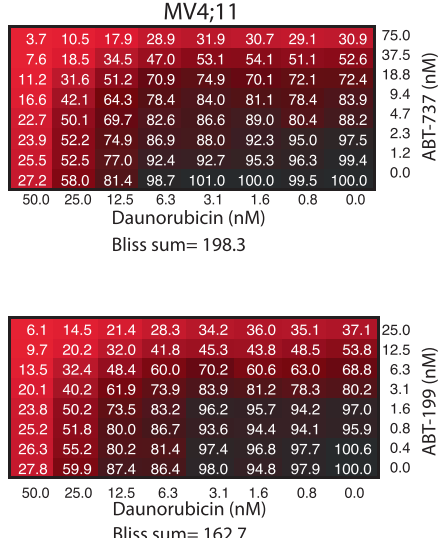
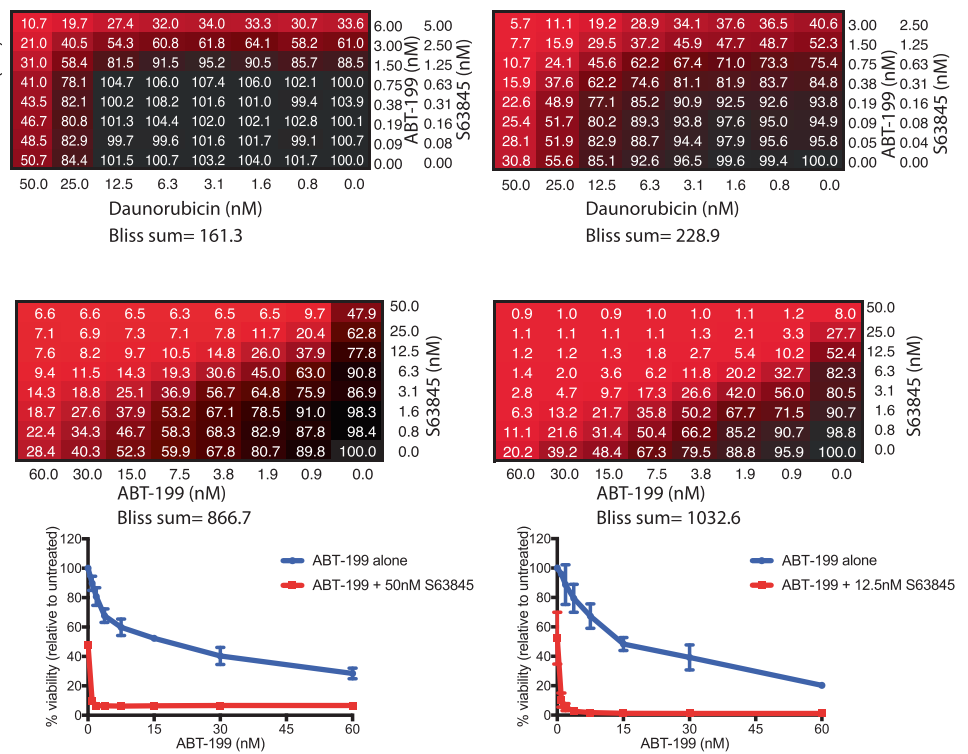
Fig. 7 Response of human $M L L$-fusion AML cell lines to $\mathrm{BH} 3$ mimetics. a EC50s of daunorubicin and BH3 mimetics. The indicated cell lines were treated for $24 \mathrm{~h}$ with drug $(0-10 \mu \mathrm{M})$ and viability was determined by CellTiter-Glo assay on a microplate reader. Values were calculated using GraphPad Prism by log-transforming the data and fitting it to a nonlinear regression. Data were determined from three independent experiments, each performed in triplicate. b Immunoblot analysis to detect indicated BCL-2 protein family members. Positive controls were lysates from the cell lines RS4;11 (for BFL-1) and U266 (for all other proteins). HSP 70 and ACTIN were used as loading controls. c Treatment of cell lines with MDM-2 inhibitor RG-7388 $(0-10 \mu \mathrm{M})$ to determine p53 status [60]. Viability (PI-negative) was determined by flow cytometry. Data represent means \pm SEM, determined from 3 independent experiments, each performed in triplicate. RS4;11 and p53 ${ }^{-1-}$ RS4;11 cell lines were employed as controls. The data indicate that $\mathrm{p} 53$ is functional in MOLM-13 and MV4;11 but not in THP-1. d-h Combination responses of THP-1 (left), Molm-13 (middle) and MV4;11 (right) human MLL-fusion AMLs to (d) daunorubicin plus ABT-737, (e) daunorubicin plus ABT-199, (f) daunorubicin plus S63845, (g) daunorubicin plus ABT-199 + S63845, or (h) ABT-199 plus S63845. Drug concentrations are indicated on $\mathrm{x}$ and $\mathrm{y}$-axes of the matrices. All lines were tested with $0-50 \mathrm{nM}$ daunorubicin but the concentration range for the $\mathrm{BH} 3$ mimetics was varied according to the EC50 of the line under test. Cell viability was determined after $24 \mathrm{~h}$ by CellTiter-Glo assay and normalised to the viability of untreated samples. The sum of Bliss scores is shown below each matrix. The data represent means determined from three independent experiments. Also shown in (h) is the response to ABT199 across the dose range as a single agent and in combination with S63845 (50 nM for THP-1 and Molm-13; $12.5 \mathrm{nM}$ for MV4;11); data shown represent means \pm SEM from three independent experiments

specific A-1331852 being the least effective. Overexpression of MCL-1 dramatically increased resistance to ABT-737 and ABT-199 but, importantly, BCL-2 overexpressing lines were as sensitive as WT/MLL-AF9 AMLs (Fig. 4). Conversely, overexpression of BCL-2 increased resistance to the MCL-1-specific S63845, but overexpression of MCL-1 did not.

Of note, when ABT-737 and S63845 were tested in vitro in combination with the other cytotoxics (Fig. 6, Supplementary Figures S8, S9), significant synergies could be achieved. With daunorubicin, those overexpressing MCL-1 were more sensitised by the MCL-1-specific S63845 (Bliss sum 227.1) than by ABT-737 (Bliss sum 99.1), and those overexpressing BCL-2 were more sensitised by the BCL-2-binding compound ABT-737 (Bliss sum 1314), although S63845 also had clear impact (Bliss sum 272.1) (Fig. 6). In view of the approximately 6-fold greater affinity of S63845 for human versus mouse MCL-1 [26], these results predict that S63845 would exhibit even greater synergy in human cells, as was demonstrated for three MLL-fusion AMLs (Fig. 7).

To investigate whether synergy with daunorubicin extended to treatment in vivo, we transplanted multiple independent WT/MLL-AF9 and BCL-2tg/MLL-AF9 AMLs into immunocompetent recipients, which were then treated with: ABT-737 or ABT-199 alone, daunorubicin alone, ABT-737 or ABT-
199 plus daunorubicin, or no drug (Fig. 7). ABT-199 showed modest efficacy as a single agent for the BCL-2 overexpressing AMLs, whereas ABT-737 did not, probably because the dosage had to be lower and ABT-199 has somewhat higher affinity for BCL-2 [25]. Mouse survival increased significantly when ABT-199 was combined with daunorubicin, for both the WT/MLL-AF9 and BCL-2tg/MLL$A F 9$ AMLs. Pertinently, a recent in vitro study of primary human AML cells found that venetoclax synergised with another anthracycline (idarubicin) and also cytarabine [13].

Looking forward, while $\mathrm{BH} 3$ mimetics and other targeted therapies seem unlikely to replace standard chemotherapeutics for AMLs, their combination with current regimens may significantly improve outcomes. For AMLs expressing both BCL-2 and MCL-1 it could be advantageous to include agents targeting both BCL-2 and MCL-1, should this prove tolerable.

Venetoclax (ABT-199), approved for use in refractory chronic lymphocytic leukaemia, is being trialled in combination therapies for other lymphoid leukaemias and lymphomas [10, 47]. Venetoclax and S63845 were recently shown to have encouraging efficacy against primary human AML cells in vitro; some AMLs were responsive to both, others only to one or the other [26]. Promising results have also been reported for venetoclax as monotherapy in a phase II trial for relapsed or refractory AML [48] and emerging preclinical and clinical data suggest that venetoclax combination therapy may significantly improve outcomes [13, 49-53]. Accordingly, venetoclax has received Breakthrough Therapy Designation for treatment-naïve AML patients ineligible to receive high dose chemotherapy.

Phase 1 clinical trials are just beginning for S63845 and two other recently reported MCL-1-specific BH3 mimetics. Valid safety concerns have been raised by reports of MCL-1 dependence for mouse cardiomyocytes [54], hepatocytes [55] and neurons [56]. Nevertheless, $\mathrm{Mcl}-\mathrm{I}^{+/-}$mice, which model the impact of permanent $50 \%$ inhibition of MCL-1, are normal and healthy [57], suggesting that a suitable therapeutic window may well be found, especially for intermittent treatment.

\section{Materials and methods}

\section{AML generation}

AMLs were generated by $M L L-A F 9$ retroviral transduction of haemopoietic stem/progenitor cells (HSPC) and reconstitution of sublethally irradiated C57BL/6-Ly5.1 mice, as described [5, 58] except that E14.5 foetal liver was the source of HSPC rather than bone marrow [22]. Mice were monitored regularly and euthanased when showing severe AML symptoms (hunched stance, ruffled coat, lethargy, 
a

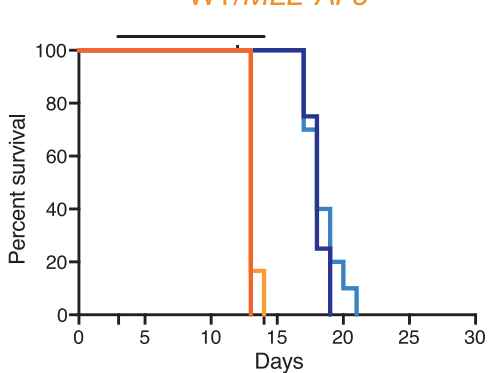

b

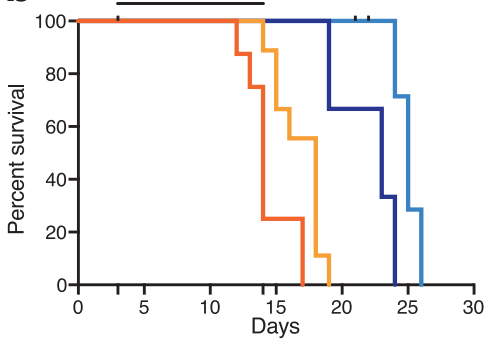

C

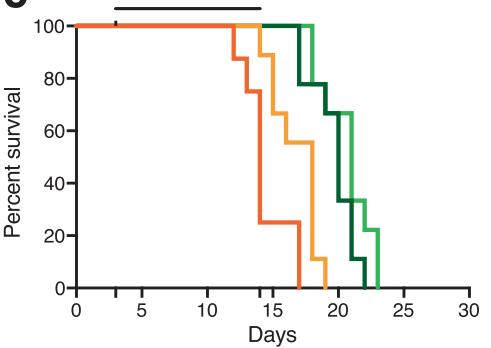

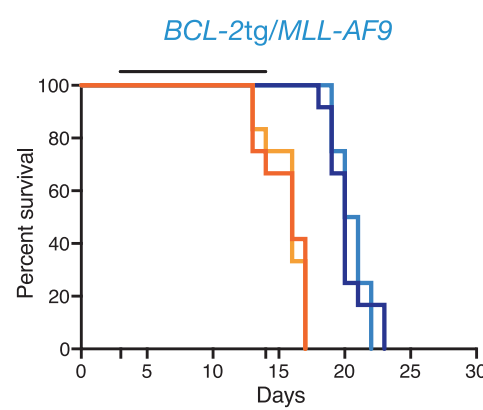

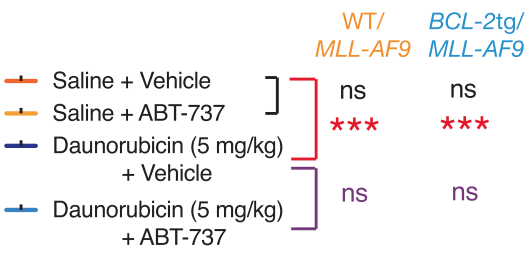

WT/ BCL-2tg/ L-AF9

** + ABT-737
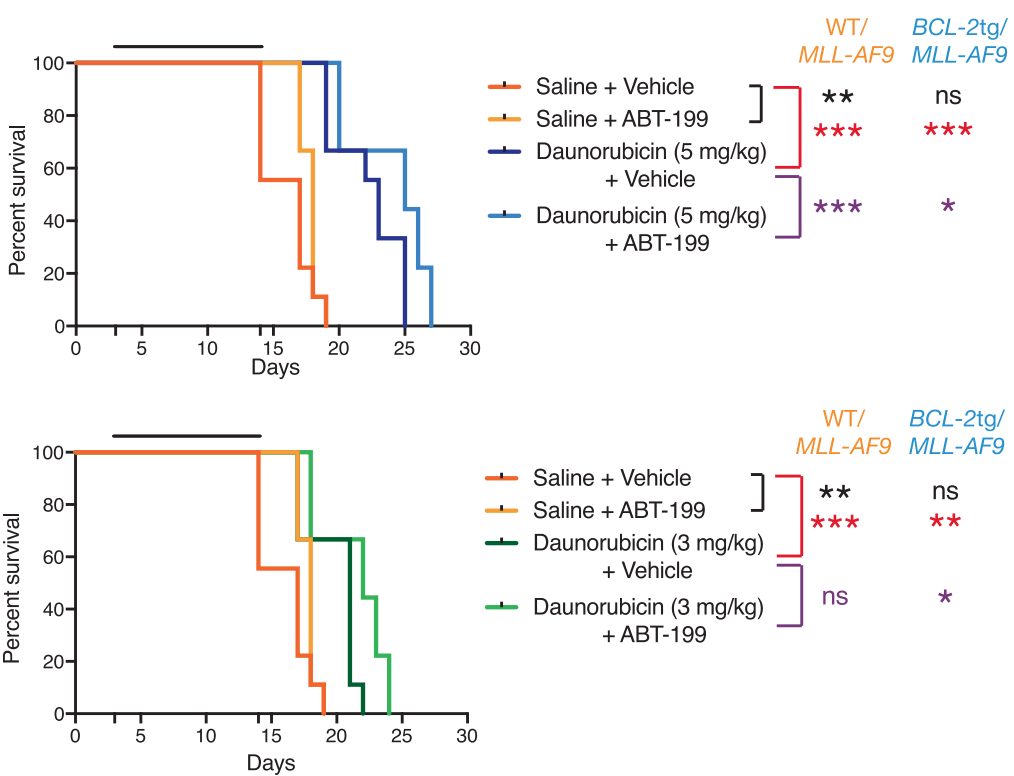

Fig. 8 Synergy between daunorubicin and $\mathrm{BH} 3$ mimetics in vivo. Kaplan-Meier survival curves for mice transplanted with $0.5 \times 10^{6}$ bone marrow cells from WT/MLL-AF9 (left) or BCL-2tg/MLL-AF9 (right) AMLs and treated with a $5 \mathrm{mg} / \mathrm{kg}$ daunorubicin $\pm 75 \mathrm{mg} / \mathrm{kg}$ ABT-737, b $5 \mathrm{mg} / \mathrm{kg}$ daunorubicin $\pm 100 \mathrm{mg} / \mathrm{kg}$ ABT- 199 and c $3 \mathrm{mg} /$ $\mathrm{kg}$ daunorubicin $\pm 100 \mathrm{mg} / \mathrm{kg}$ ABT-199. Daunorubicin was administered intravenously on days 1, 4 and 9; and ABT-737 or ABT-199 was administered intraperitoneally or by oral gavage respectively on days 1-5 and 8-12; controls received saline and ABT-737 vehicle. Transplanted mice were monitored daily for symptoms of AML and

anaemia and splenomegaly) or significant weight loss. Histological and haemopoietic analysis is detailed in the Supplementary Methods. Mouse survival analysis utilised GraphPad Prism and significance was determined using Log-rank (Mantel-Cox) test.

\section{Cell lines}

Human MLL-fusion AML cell lines MV4;11 [37] and THP1 [35] were from ATCC (American Type Culture Collection; VI, USA) and Molm-13 [36] from DSMZ (Deutsche Sammlung von Mikroorganismen und Zellkulturen; Leibniz, Germany). Culture medium was RPMI $1640+10 \%$ FBS, with inclusion of $50 \mu \mathrm{M} 2$-mercaptoethanol for THP-1 cells. euthanased if morbidly ill. 3-4 independent tumours of each genotype were treated, with 3 mice per tumour per treatment arm. WT/MLL-AF9 \#1501, \#1533, \#2036 and \#1742 (daunorubicin \pm ABT-737 only), $B C L-2 \operatorname{tg} / M L L-A F 9$ \#1537, \#1563, \#2028 and \#1538 (daunorubicin \pm ABT-737 only). Statistical significance between saline versus BH3 mimetic alone (black), saline vs daunorubicin alone (red) or daunorubicin vs daunorubicin + BH3 mimetic (purple) was determined by Log-rank (Mantle-Cox) test: $\mathrm{ns}=$ not significant, ${ }^{*} p<0.05,{ }^{*} p<$ $0.01, * * * p<0.001$

\section{In vitro drug treatment}

Short-term MLL-AF9 AML lines were generated as described [22] and drug sensitivity was determined by flow cytometric analysis of apoptosis or high throughput CellTiter-Glo (Promega, Madison WI, USA) measurement of metabolic activity (see Supplementary Methods). Drug sensitivity of human $M L L$-fusion AML cell lines was determined by CellTiter-Glo assay on a microplate reader (LUMIstar OPTIMA, Germany).

\section{In vivo drug treatment}

Primary tumours were expanded in vivo and transplanted into non-irradiated recipient mice as previously described 
[22] to generate secondary tumours, which developed after 13-50 d. Drug treatment of transplanted secondary tumours was performed as published [22, 59]. Briefly, this involved intravenous injection of daunorubicin $(3 \mathrm{mg} / \mathrm{kg}$ or $5 \mathrm{mg} / \mathrm{kg}$ ) or an equal volume of saline on days 1,4 and 9 , followed by a flush of saline, and either ABT-737 $(75 \mathrm{mg} / \mathrm{kg}$ injected intraperitoneally) or ABT-199 (100 mg/kg administered by oral gavage), or equal volume of vehicle, on days 1 to 5 and days 8 to 12 . Mice were euthanased at ethical endpoint.

See Supplementary Materials and Methods for mice, haemopoietic analysis, drug treatment and western blotting.

Acknowledgements We thank our colleagues JM Adams, A Wei and A Strasser for review of the manuscript; S Glaser, H Jousset, David Huang, K Lowes, D Segal and C Burns for advice and reagents; $M$ Robati, P Novello, G Siciliano, K Hughes, J Corbin and J McManus for technical assistance and mouse husbandry; and the institute's flow cytometry and histology facilities for skilled support. This work was supported by funding from the NHMRC (Australia) (program grants 1016701, 113577 and project grants 1058746, 1122783); US Leukaemia and Lymphoma Society Specialized Center for Research Grant 7001-13; Leukaemia Foundation of Australia; and infrastructure support to the institute from the NHMRC Independent Research Institute Infrastructure Support Scheme (IRISS 9000220) and the Victorian State Government Operational Infrastructure Support (OIS).

Author contributions SC conceived the project; NSA and RAB performed most of the experiments, with contributions from ZX, CJV and $\mathrm{AN}$ and co-supervision by CJV and SC; SC and NSA wrote the manuscript.

\section{Compliance with ethical standards}

Conflict of interest The Walter and Eliza Hall Institute (WEHI) (but not the authors) received research funding from Genentech and Abbott Laboratories (now Abbvie) for the development of BH3 mimetics and as a consequence now receives royalty income. WEHI scientists (but not the authors) have also received research funding from Servier for preclinical testing of $\mathrm{MCL}-1^{-}$specific $\mathrm{BH} 3$ mimetics.

Open Access This article is licensed under a Creative Commons Attribution 4.0 International License, which permits use, sharing, adaptation, distribution and reproduction in any medium or format, as long as you give appropriate credit to the original author(s) and the source, provide a link to the Creative Commons license, and indicate if changes were made. The images or other third party material in this article are included in the article's Creative Commons license, unless indicated otherwise in a credit line to the material. If material is not included in the article's Creative Commons license and your intended use is not permitted by statutory regulation or exceeds the permitted use, you will need to obtain permission directly from the copyright holder. To view a copy of this license, visit http://creativecommons. org/licenses/by/4.0/.

\section{References}

1. Cancer Genome Atlas Research N. Genomic and epigenomic landscapes of adult de novo acute myeloid leukemia. N Engl $\mathrm{J}$ Med. 2013;368:2059-74.
2. Krivtsov AV, Armstrong SA. MLL translocations, histone modifications and leukaemia stem-cell development. Nat Rev Cancer. 2007;7:823-33.

3. Slany RK. The molecular mechanics of mixed lineage leukemia. Oncogene. 2016;35:5215-23.

4. Ayton PM, Cleary ML. Transformation of myeloid progenitors by MLL oncoproteins is dependent on Hoxa7 and Hoxa9. Genes Dev. 2003;17:2298-307.

5. Krivtsov AV, Twomey D, Feng Z, Stubbs MC, Wang Y, Faber J, et al. Transformation from committed progenitor to leukaemia stem cell initiated by MLL-AF9. Nature. 2006;442:818-22.

6. Estey E. Acute myeloid leukemia: 2016 Update on riskstratification and management. Am J Hematol. 2016;91:824-46.

7. Reese ND, Schiller GJ. High-dose cytarabine (HD araC) in the treatment of leukemias: a review. Curr Hematol Malig Rep. 2013;8:141-8.

8. Burden DA, Osheroff N. Mechanism of action of eukaryotic topoisomerase II and drugs targeted to the enzyme. Biochim Biophys Acta. 1998;1400:139-54.

9. Ferraro C, Quemeneur L, Prigent AF, Taverne C, Revillard JP, Bonnefoy-Berard N. Anthracyclines trigger apoptosis of both $\mathrm{G}_{0^{-}}$ $\mathrm{G}_{1}$ and cycling peripheral blood lymphocytes and induce massive deletion of mature T and B cells. Cancer Res. 2000;60:1901-7.

10. Cory S, Roberts A, Colman PM, Adams JM. Targeting BCL-2like Proteins to Kill Cancer Cells. Trends Cancer. 2016;2:443-60.

11. Xiang Z, Luo H, Payton JE, Cain J, Ley TJ, Opferman JT, et al. Mcl1 haploinsufficiency protects mice from Myc-induced acute myeloid leukemia. J Clin Invest. 2010;120:2109-18.

12. Niu X, Wang G, Wang Y, Caldwell JT, Edwards H, Xie C, et al. Acute myeloid leukemia cells harboring MLL fusion genes or with the acute promyelocytic leukemia phenotype are sensitive to the Bcl-2-selective inhibitor ABT-199. Leukemia. 2014; $28: 1557-60$.

13. Teh TC, Nguyen NY, Moujalled DM, Segal D, Pomilio G, Rijal $\mathrm{S}$, et al. Enhancing venetoclax activity in acute myeloid leukemia by co-targeting MCL1. Leukemia 2018;32:303-12.

14. Kaufmann SH, Karp JE, Svingen PA, Krajewski S, Burke PJ, Gore SD, et al. Elevated expression of the apoptotic regulator Mcl-1 at the time of leukemic relapse. Blood. 1998;91:991-1000.

15. Glaser S, Lee EF, Trounson E, Bouillet P, Wei A, Fairlie WD, et al. Anti-apoptotic Mcl-1 is essential for the development and sustained growth of acute myeloid leukemia. Genes Dev. 2012;26:120-5.

16. Chen R, Wierda WG, Chubb S, Hawtin RE, Fox JA, Keating MJ, et al. Mechanism of action of SNS-032, a novel cyclin-dependent kinase inhibitor, in chronic lymphocytic leukemia. Blood. 2009;113:4637-45.

17. Thomas D, Powell JA, Vergez F, Segal DH, Nguyen NY, Baker A, et al. Targeting acute myeloid leukemia by dual inhibition of PI3K signaling and Cdk9-mediated Mcl-1 transcription. Blood. 2013;122:738-48.

18. Podar K, Gouill SL, Zhang J, Opferman JT, Zorn E, Tai YT, et al. A pivotal role for $\mathrm{Mcl}-1$ in Bortezomib-induced apoptosis. Oncogene. 2008;27:721-31.

19. Csizmar CM, Kim DH, Sachs Z. The role of the proteasome in AML. Blood Cancer J. 2016;6:e503.

20. Ogilvy S, Metcalf D, Print CG, Bath ML, Harris AW, Adams JM. Constitutive bcl-2 expression throughout the hematopoietic compartment affects multiple lineages and enhances progenitor cell survival. Proc Natl Acad Sci USA. 1999;96:14943-8.

21. Campbell KJ, Bath ML, Turner ML, Vandenberg CJ, Bouillet P, Metcalf D, et al. Elevated Mcl-1 perturbs lymphopoiesis, promotes transformation of hematopoietic stem/progenitor cells, and enhances drug resistance. Blood. 2010;116:3197-207. 
22. Bilardi RA, Anstee NS, Glaser SP, Robati M, Vandenberg CJ, Cory S. Impact of loss of BH3-only proteins on the development and treatment of MLL-fusion gene-driven AML in mice. Cell Death Dis. 2016;7:e2351.

23. Lam LT, Pickeral OK, Peng AC, Rosenwald A, Hurt EM, Giltnane JM, et al. Genomic-scale measurement of mRNA turnover and the mechanisms of action of the anti-cancer drug flavopiridol. Genome Biol. 2001;2:RESEARCH0041.

24. Oltersdorf T, Elmore SW, Shoemaker AR, Armstrong RC, Augeri DJ, Belli BA, et al. An inhibitor of Bcl-2 family proteins induces regression of solid tumours. Nature. 2005;435:677-81.

25. Souers AJ, Leverson JD, Boghaert ER, Ackler SL, Catron ND, Chen J, et al. ABT-199, a potent and selective BCL-2 inhibitor, achieves antitumor activity while sparing platelets. Nat Med. 2013;19:202-8.

26. Kotschy A, Szlavik Z, Murray J, Davidson J, Maragno AL, Le Toumelin-Braizat G, et al. The MCL1 inhibitor S63845 is tolerable and effective in diverse cancer models. Nature. 2016;538:477-82.

27. Tao ZF, Hasvold L, Wang L, Wang X, Petros AM, Park CH, et al. Discovery of a Potent and Selective BCL-XL Inhibitor with in Vivo Activity. ACS Med Chem Lett. 2014;5:1088-93.

28. van Delft MF, Wei AH, Mason KD, Vandenberg CJ, Chen L, Czabotar PE, et al. The BH3 mimetic ABT-737 targets selective $\mathrm{Bcl}-2$ proteins and efficiently induces apoptosis via $\mathrm{Bak} / \mathrm{Bax}$ if Mcl-1 is neutralized. Cancer Cell. 2006;10:389-99.

29. Willis SN, Chen L, Dewson G, Wei A, Naik E, Fletcher JI, et al. Proapoptotic Bak is sequestered by Mcl-1 and Bcl-xL, but not Bcl-2, until displaced by BH3-only proteins. Genes Dev. 2005;19:1294-305.

30. Gomez-Bougie P, Wuilleme-Toumi S, Menoret E, Trichet V, Robillard N, Philippe M, et al. Noxa up-regulation and Mcl-1 cleavage are associated to apoptosis induction by bortezomib in multiple myeloma. Cancer Res. 2007;67:5418-24.

31. Czabotar PE, Lee EF, van Delft MF, Day CL, Smith BJ, Huang DC, et al. Structural insights into the degradation of Mcl-1 induced by $\mathrm{BH} 3$ domains. Proc Natl Acad Sci USA. 2007;104:6217-22.

32. Khwaja A, Bjorkholm M, Gale RE, Levine RL, Jordan CT, Ehninger G, et al. Acute myeloid leukaemia. Nat Rev Dis Prim. 2016;2:16010.

33. Foucquier J, Guedj M. Analysis of drug combinations: current methodological landscape. Pharmacol Res Perspect. 2015;3: e00149.

34. Leverson JD, Phillips DC, Mitten MJ, Boghaert ER, Diaz D, Tahir SK, et al. Exploiting selective BCL-2 family inhibitors to dissect cell survival dependencies and define improved strategies for cancer therapy. Sci Transl Med. 2015;7:279ra240.

35. Tsuchiya S, Yamabe M, Yamaguchi Y, Kobayashi Y, Konno T, Tada K. Establishment and characterization of a human acute monocytic leukemia cell line (THP-1). Int $\mathrm{J}$ Cancer. 1980;26:171-6.

36. Matsuo Y, MacLeod RA, Uphoff CC, Drexler HG, Nishizaki C, Katayama Y, et al. Two acute monocytic leukemia (AML-M5a) cell lines (MOLM-13 and MOLM-14) with interclonal phenotypic heterogeneity showing MLL-AF9 fusion resulting from an occult chromosome insertion, ins(11;9)(q23;p22p23). Leukemia. 1997;11:1469-77.

37. Lange B, Valtieri M, Santoli D, Caracciolo D, Mavilio F, Gemperlein I, et al. Growth factor requirements of childhood acute leukemia: establishment of GM-CSF-dependent cell lines. Blood. 1987;70:192-9.

38. Campos L, Rouault J-P, Sabido O, Oriol P, Roubi N, Vasselon C, et al. High expression of bcl-2 protein in acute myeloid leukemia cells is associated with poor response to chemotherapy. Blood. 1993;81:3091-6.

39. Strasser A, Harris AW, Bath ML, Cory S. Novel primitive lymphoid tumours induced in transgenic mice by cooperation between myc and $b c l-2$. Nature. 1990;348:331-3.

40. Slape CI, Saw J, Jowett JB, Aplan PD, Strasser A, Jane SM, et al. Inhibition of apoptosis by BCL2 prevents leukemic transformation of a murine myelodysplastic syndrome. Blood. 2012;120: 2475-83.

41. Campbell KJ, Gray DH, Anstee N, Strasser A, Cory S. Elevated Mcl-1 inhibits thymocyte apoptosis and alters thymic selection. Cell Death Differ. 2012;19:1962-71.

42. Yecies D, Carlson NE, Deng J, Letai A. Acquired resistance to ABT-737 in lymphoma cells that up-regulate MCL-1 and BFL-1. Blood. 2010;115:3304-13.

43. Lessene G, Czabotar PE, Sleebs BE, Zobel K, Lowes KL, Adams JM, et al. Structure-guided design of a selective BCL-XL inhibitor. Nat Chem Biol. 2013;9:390-7.

44. Chen L, Willis SN, Wei A, Smith BJ, Fletcher JI, Hinds MG, et al. Differential targeting of pro-survival Bcl-2 proteins by their BH3only ligands allows complementary apoptotic function. Mol Cell. 2005; 17:393-403.

45. Kuwana T, Bouchier-Hayes L, Chipuk JE, Bonzon C, Sullivan BA, Green DR, et al. BH3 Domains of BH3-Only Proteins Differentially Regulate Bax-Mediated Mitochondrial Membrane Permeabilization Both Directly and Indirectly. Mol Cell. 2005; 17:525-35.

46. Ashkenazi A, Fairbrother WJ, Leverson JD, Souers AJ. From basic apoptosis discoveries to advanced selective BCL-2 family inhibitors. Nat Rev Drug Discov. 2017;16:273-84.

47. Sarosiek KA, Letai A. Directly targeting the mitochondrial pathway of apoptosis for cancer therapy using $\mathrm{BH} 3$ mimetics - recent successes, current challenges and future promise. FEBS J. 2016;283:3523-33.

48. Konopleva M, Pollyea DA, Potluri J, Chyla B, Hogdal L, Busman $\mathrm{T}$, et al. Efficacy and biological correlates of response in a phase ii study of venetoclax monotherapy in patients with acute Myelogenous Leukemia. Cancer Discov. 2016;6:1106-17.

49. DiNardo CD, Pratz KW, Letai A, Jonas BA, Wei AH, Thirman M, et al. Safety and preliminary efficacy of venetoclax with decitabine or azacitidine in elderly patients with previously untreated acute myeloid leukaemia: a non-randomised, open-label, phase $1 \mathrm{~b}$ study. Lancet Oncol. 2018;19:216-28.

50. Yogarajah M, Stone RM. A concise review of BCL-2 inhibition in acute myeloid leukemia. Expert Rev Hematol. 2018;11:145-54.

51. Naqvi K, Konopleva M, Ravandi F. Targeted therapies In Acute Myeloid Leukemia: a Focus on FLT-3 inhibitors and ABT199. Expert Rev Hematol. 2017;10:863-74.

52. Pan R, Ruvolo V, Mu H, Leverson JD, Nichols G, Reed JC, et al. Synthetic Lethality of Combined Bcl-2 Inhibition and p53 Activation in AML: Mechanisms and Superior Antileukemic Efficacy. Cancer Cell. 2017;32:748-60 e746.

53. Konopleva M, Letai A BCL-2 inhibition in AML - an unexpected bonus? Blood 2018;132:1007-1012.

54. Thomas RL, Roberts DJ, Kubli DA, Lee Y, Quinsay MN, Owens JB, et al. Loss of MCL-1 leads to impaired autophagy and rapid development of heart failure. Genes Dev. 2013;27: 1365-77.

55. Vick B, Weber A, Urbanik T, Maass T, Teufel A, Krammer PH, et al. Knockout of myeloid cell leukemia-1 induces liver damage and increases apoptosis susceptibility of murine hepatocytes. Hepatology. 2009;49:627-36.

56. Arbour N, Vanderluit JL, Le Grand JN, Jahani-Asl A, Ruzhynsky VA, Cheung EC, et al. Mcl-1 is a key regulator of apoptosis 
during CNS development and after DNA damage. J Neurosci. 2008;28:6068-78.

57. Rinkenberger JL, Horning S, Klocke B, Roth K, Korsmeyer SJ. Mcl-1 deficiency results in peri-implantation embryonic lethality. Genes Dev. 2000;14:23-27.

58. Somervaille TC, Cleary ML. Identification and characterization of leukemia stem cells in murine MLL-AF9 acute myeloid leukemia. Cancer Cell. 2006;10:257-68.
59. Vandenberg CJ, Cory S. ABT-199, a new Bcl-2-specific BH3 mimetic, has in vivo efficacy against aggressive Myc-driven mouse lymphomas without provoking thrombocytopenia. Blood. 2013;121:2285-8.

60. Tovar C, Graves B, Packman K, Filipovic Z, Higgins B, Xia M, et al. MDM2 small-molecule antagonist RG7112 activates p53 signaling and regresses human tumors in preclinical cancer models. Cancer Res. 2013;73:2587-97. 